\title{
MEASURED AND CALCULATED RESPONSE OF NEUTRON SPECTRUM INDICES IN THE ENRICO FERMI FAST BREEDER REACTOR
}

\author{
R. E. HORNE \\ E. M. PAGE \\ D. A. DAAVETTILA $\dagger$ \\ J. C. MONTFORT*
}

\footnotetext{
† MICHIGAN COLLEGE OF MINING \& TECHNOLOGY, HOUGHTON, MICHIGAN

*ELECTRICITE DE FRANCE
} 


\section{DISCLAIMER}

This report was prepared as an account of work sponsored by an agency of the United States Government. Neither the United States Government nor any agency Thereof, nor any of their employees, makes any warranty, express or implied, or assumes any legal liability or responsibility for the accuracy, completeness, or usefulness of any information, apparatus, product, or process disclosed, or represents that its use would not infringe privately owned rights. Reference herein to any specific commercial product, process, or service by trade name, trademark, manufacturer, or otherwise does not necessarily constitute or imply its endorsement, recommendation, or favoring by the United States Government or any agency thereof. The views and opinions of authors expressed herein do not necessarily state or reflect those of the United States Government or any agency thereof. 


\section{DISCLAIMER}

Portions of this document may be illegible in electronic image products. Images are produced from the best available original document. 
-

,

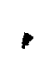




\section{FOREW ORD}

This is one of a series of reports on the low-power (up to $1 \mathrm{Mwt}$ ) and high-power (up to $200 \mathrm{Mwt}$ ) nuclear testing of the Enrico Fermi Fast Breeder Reactor. The Nuclear Test Program was planned, directed, and evaluated by Atomic Power Development Associates, Inc. (APDA). The tests were conducted by Power Reactor Development Company (PRDC), who own and operate the reactor proper. The steam generators and electrical generation facilities are owned by The Detroit Edison Company (DECo).

Many people have contributed to the success of nuclear testing of the Fermi reactor. Listed below are the names of those people, exclusive of the authors, who made a significant contribution to some phase of the work reported in this document.

\section{APDA}

C. E. Branyan

H. A. Wilber

\section{PRDC}

E. L. Alexanderson

J. Burke

D. Erdman **

M. Esau

The authors also gratefully acknowledge the efforts of N. G. A. Maene, of Studiecentrum voor Kernenergie, Mol, Belgium, in generating neutron spectra from the fission counter data, and the cooperation of the Argonne National Laboratory in providing the absolute fission counters used in the performance of this work.

\footnotetext{
* Presently associated with Power Reactor Development Company * * Presently associated with Potomac Electric Power Company
} 
○

,

○ 
LIST OF ILLUSTRATIONS ..................... vii

LIST OF TABLES ........................ ix

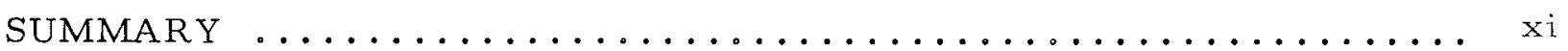

I. PURPOSE OF $\mathrm{TEST} \ldots \ldots \ldots \ldots \ldots \ldots \ldots \ldots \ldots \ldots \ldots \ldots \ldots$

II. DESCRIPTION OF THE ENRICO FERMI REACTOR ........ 3

A. GENERAL DESCRIPTION ................... 3

B. REACTOR CORE AND BLANKET SUBASSEMBLIES ....... 8

1. Core Subassemblies .................... 8

2. Radial Blanket Subassemblies ................. 9

III. EXPERIMENTAL PROCEDURE $\ldots \ldots \ldots \ldots \ldots \ldots \ldots \ldots$

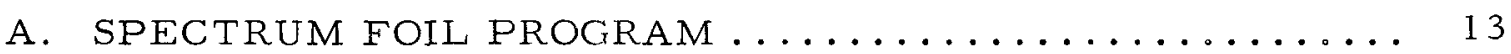

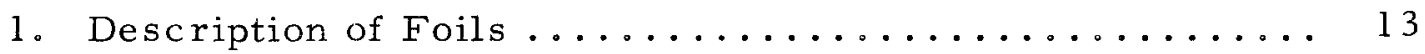

2. Special Subassemblies .................... 14

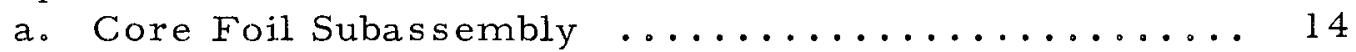

b. Blanket Foil Subassembly .................. 14

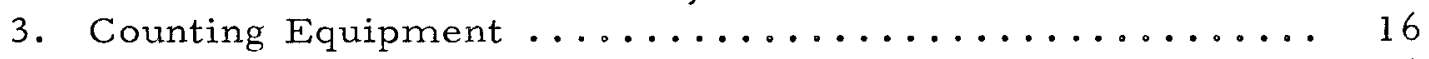

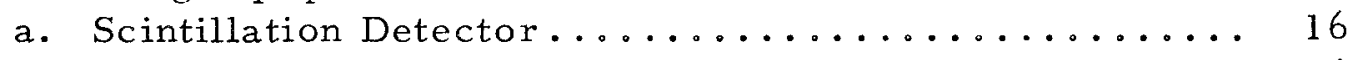

b. Linear Amplifier and Pulse Height Analyzer ........ 16

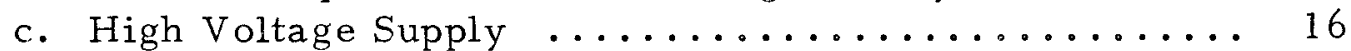

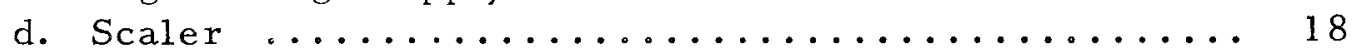

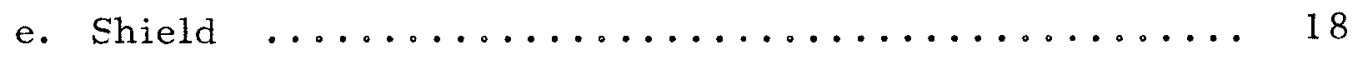

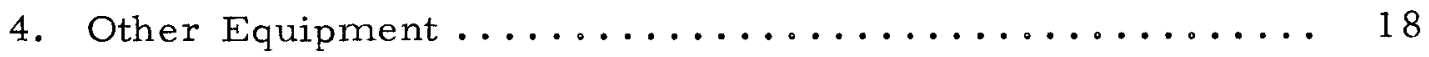

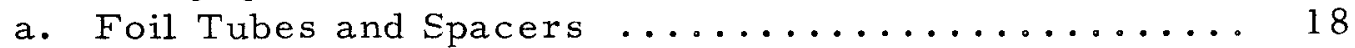

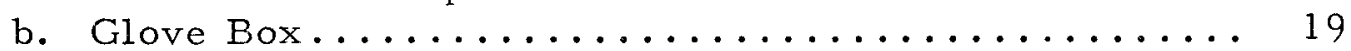

c. Temporary Instrument Thimble ............... 19

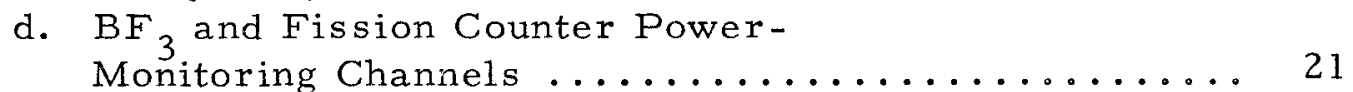

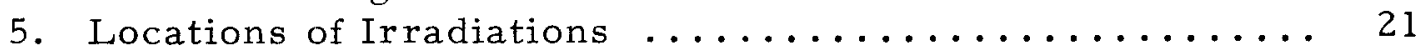

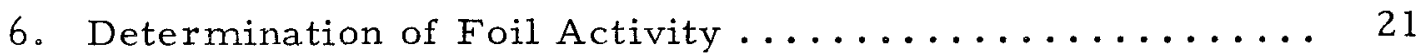

a. Calibration of Counting Equipment ........... 21

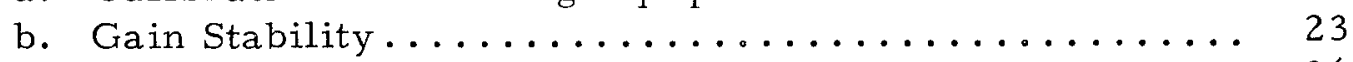

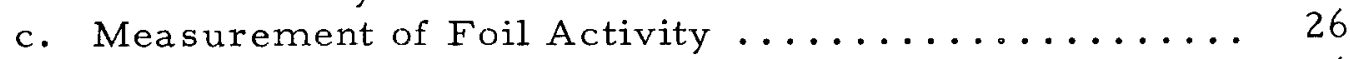

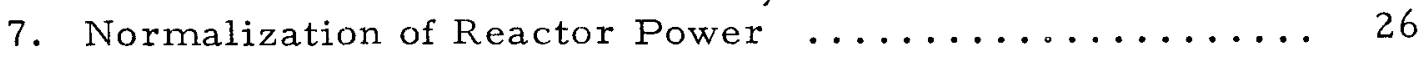

B. FISSION COUNTER PROGRAM $\ldots \ldots \ldots \ldots \ldots \ldots \ldots \ldots \ldots \ldots$ 


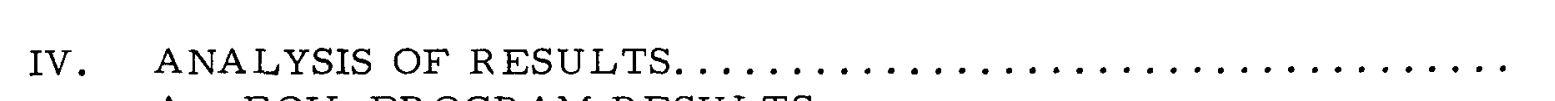

A. FOIL PROGR AM RESULTS................... 41

1. Data Reduction ........................ 41

a. Simple Deday ....................... 41

b. Fission Product Decay.................. 41

2. Experimental Results ................... 42

3. Comparis on with Calculation ................ 44

B. FISSION COUNTER PROGR AM RESULTS. . . . . . . . . . . 47

1. Axial Traverses.......................... 47

2. Neutron Spectrum Determination .............. 54

C. SOURCES OF EXPERIMENTAL ERROR .............. 55

1. Power Normalization. .................. 57

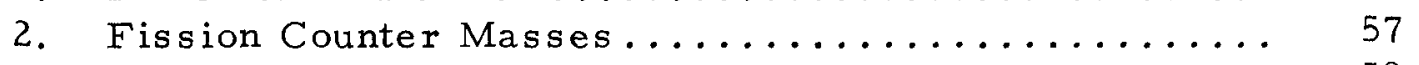

3. Stainless Steel Scattering................. 58

4. Counting Statistics, Background, and

Impurity Is otopes.................. 58

v. CONCLUSIONS ......................... 61

REFERENCES. ......................... 63 
Figure No.

Page

1

Perspective View of Reactor ............... 4

2

Reactor Cross Section .................... 5

3 Location of Neutron-Counter Tubes in Graphite Shield.... 7

4 Isometric View of a Core Subassembly............ 10

5 Is ometric View of a Radial Blanket Subassembly ...... 11

6 Details of Core Fuel and Core Foil Subassemblies....... 15

$7 \quad$ Block Diagram of Scintillation Equipment ......... 17

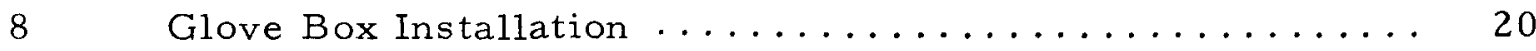

$9 \quad$ Spectral Measurement Positions .............. 22

10 Gamma-Ray Energy as a Function of Linear Amplifier

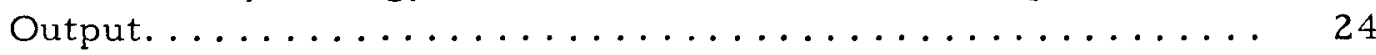

11 Pulse Height Analysis of Standard Cesium Source...... 25

12 Integral Cs-137 Count Rate as a Function of High-

Voltage Deviation from that Required to Obtain

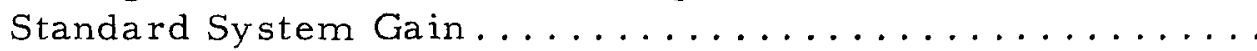

13 Pulse Height Analysis of Irradiated Gold Foil . . . . . . . 28

14 Pulse Height Analysis of Irradiated Aluminum Foil ... . 29

15 Pulse Height Analysis of Irradiated Iron and Manganese

Foils ............................. 30

16 Pulse Height Analysis of Irradiated Nickel Foil ...... 31

17 Half-Life Determination of Aluminum Foil ........ 32

18 Half-Life Determination of Nickel Foil .......... 33 


\section{LIST OF ILLUSTRATIONS}

Figure No.

Page

19 Half-Life Determination of Gold Foil .......... 34

20 Half-Life Determination of Iron Foil $\ldots \ldots \ldots \ldots \ldots$

21 Half-Life Determination of Manganese Foil ........ 36

22 Measured and Calculated Response Distributions

at Different Lattice Positions.................... 45

$23 \quad$ Axial Response Distributions ............... 46

24 Core Midplane Radial Response Distributions . . . . . . . 46

25 U-234 Axial Fission Distribution in Empty Safety Rod

Channel of the EFFBR.................. 48

26 U-236 Axial Fission Distribution in Empty Safety Rod

Channel of the EFFBR.................. 49

27 Axial Fission Distribution for Natural Uranium in Core A. . 50

28 U-235 Axial Fission Distribution in the Temporary

Instrument Thimble (PO3-POO) .............. 5 I

$29 \quad$ Pu-239 Axial Fission Distribution.............. 52

$30 \quad$ Results of Spectrum Measurements ............. 56

31 Comparison of Fission Counter Geometries.......... 59 


\section{LIST OF TABLES}

Table No.

$\underline{\text { Title }}$

Page

$1 \quad$ Foils for Neutron Spectrum Program .............. 14

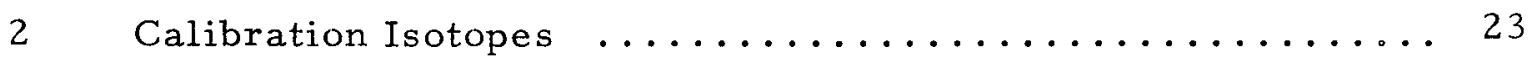

3 Integrated Counts, Currents, and Ratios Obtained for Power Normalization ................... 37

$4 \quad$ Adjusted Counts and Currents and Adjustment Factors Used for Power Normalization ............ 37

5 Uranium Absolute Fission Counter Loadings ........... 39

6 Plutonium Absolute Fission Counter Loadings . . . . . . . . 39

$7 \quad$ Normalized Foil Activity $\ldots \ldots \ldots \ldots \ldots \ldots \ldots \ldots \ldots$

8. The 95\% Confidence Limits for Spectrum Foil Results as a Function of Radial Location ............... 42

9. Fission Ratios in the Temporary Instrument Thimble at Core Midplane................... 53

10. Measured and Calculated Fission Ratios $\ldots \ldots \ldots \ldots \ldots$ 
○

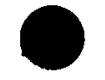

. 


\section{SUMMARY}

Comparicon of measured threshold-type reaction rate distributions with calculations indicate that standard multigroup techniques for the calculation of high energy fluxes at distances of the order of $75 \mathrm{~cm}$ from the core boundary can be used with confidence. These data together with the data

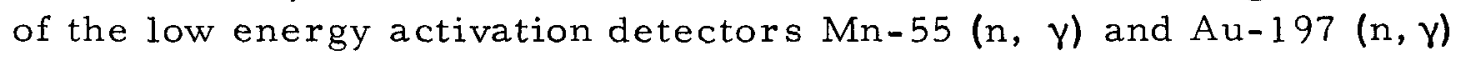
support earlier U-235 scans in showing that low energy reaction rates rise severely near the edge of the blanket. These rises are currently being confirmed by temperature measurements.

Absolute reaction rates obtained with fission counters support the general contention for fast reactors that the lower energy flux is greater than calculated. A reverse trend is indicated for the higher energy fluxes, but accurate spectrum measurements were found to be hampered by uncertainties in counter loadings and difficulties in power normalization. 


\section{PURPOSE OF TEST}

The purpose of the neutron spectrum test program was to investigate the feasibility of performing neutron spectrum measurements in a fast power reactor such as the Enrico Fermi Fast Breeder Reactor, to obtain preliminary spectral data, and to measure reaction rates at points relatively far into the sodium pool above the reactor core. Spectrum information was obtained by measuring selected reaction rates of six isotopes by foil ir radiation at a number of positions in the core and blanket and by making axial traverses with five different absolute fission counters (U-234, U-235, U-238, $\mathrm{Pu}-239$, and $\mathrm{Pu}-240$ ) in the temporary instrument thimble (TIT). Traverses extending quite far into the sodium pool were made with the U-235 and Pu-239 counters to provide reaction rate data at points relatively distant from the core. 
•

• 


\section{DESCRIPTION OF THE ENRICO FERMI REACTOR}

\section{A. GENERAL DESCRIPTION}

The Enrico Fermi reactor and its associated structures are shown in perspective in Figure 1. The reactor is contained in a stainless steel vessel sealed at the top by a rotating shield plug, which supports the control mechanisms, the holddown mechanism, and the fuel-handling mechanism. The reactor vessel is surrounded by boronated and plain graphite neutron shielding material contained inside the primary shield tank. The reactor is of the fast breeder type, cooled by sodium and operated at essentially atmospheric pressure. The maximum reactor power with the first core loading (Core A) is $200 \mathrm{Mwt}$.

The core and blanket, located in the lower reactor vessel, consists of square subassemblies containing the fuel pins and blanket rods arranged to approximate a cylinder about 80 inches in diameter and 70 inches high. The core, contained in the central portion of the core subassemblies, approximates a right cylinder 31 inches in diameter and 31 inches high; it is axially and radially surrounded by breeder blankets. The fuel in Core A consists of zirconium-clad pins containing U-10 w/o molybdenum alloy with the uranium enriched to $25.6 \mathrm{w} / \mathrm{o}$ U-235. Each fuel subassembly in the core contains 140 fuel pins having a total mass of approximately 4.75 kilograms of U-235 per subassembly. The blanket is depleted U-3 w/o molybdenum alloy.

The reactor cross section, shown in Figure 2, indicates the placement of individual components within the lower reactor vessel. There is a total of 149 central lattice positions occupied by core and inner radial blanket subassemblies, the neutron source, and the two operating control and eight safety rod channels. The lattice positions surrounding the inner radial blanket comprise the outer blanket area; when filled with outer radial blanket subassemblies, these positions form an annular region whose top and bottom are at the same elevation as the top and bottom of the inner radial blanket. Surrounding the outer radial blanket are lattice positions used for stainless steel subassemblies which provide thermal and neutron shielding.

The reactor lattice is divided by two datum lines through the center of the reactor core. These lines have the same relationship as the $\mathrm{X}$ and $\mathrm{Y}$ axes in a coordinate system. The center subassembly location is designated P00-P00, and each subassembly location surrounding this location has a position designated by its distance from the axes. 


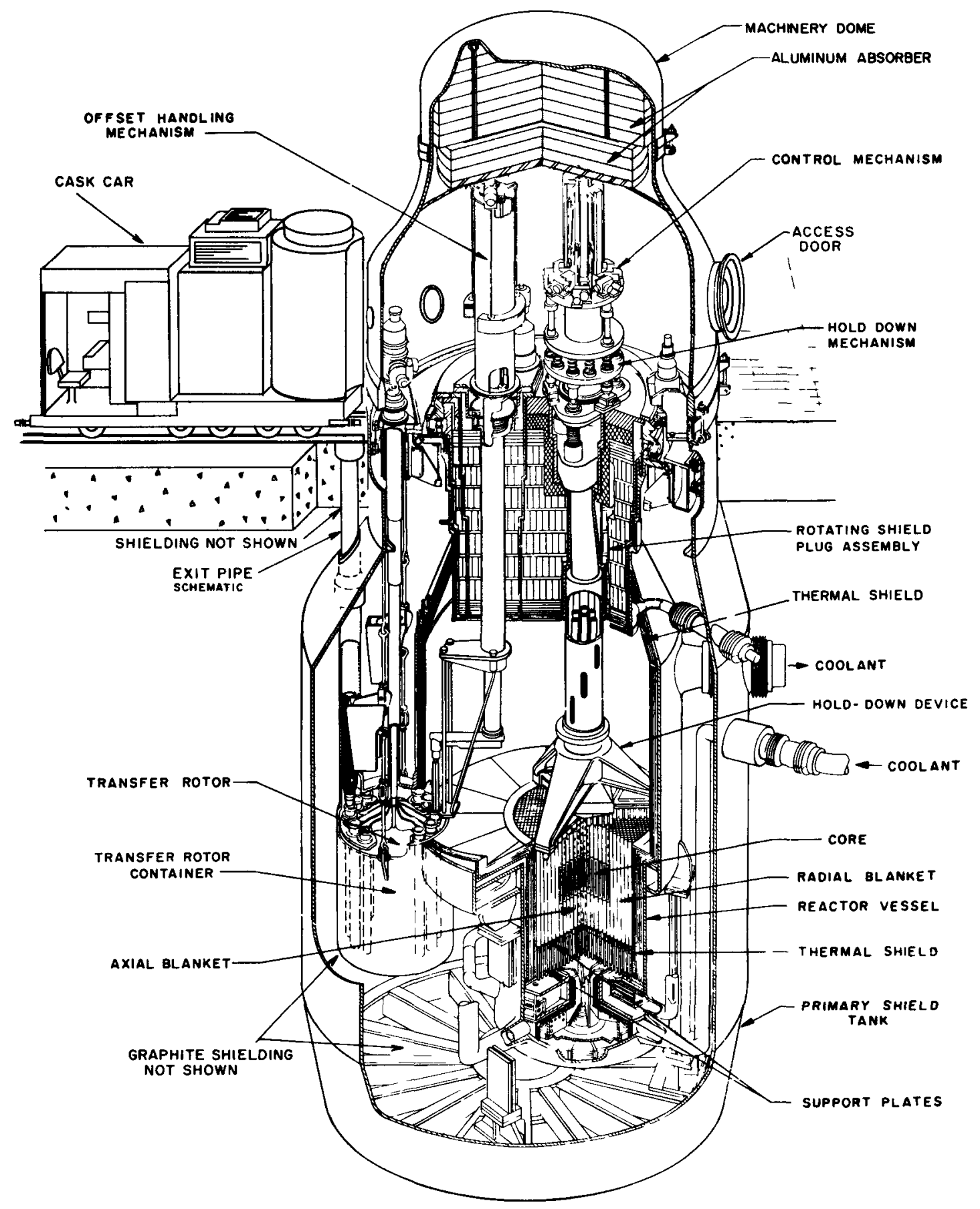




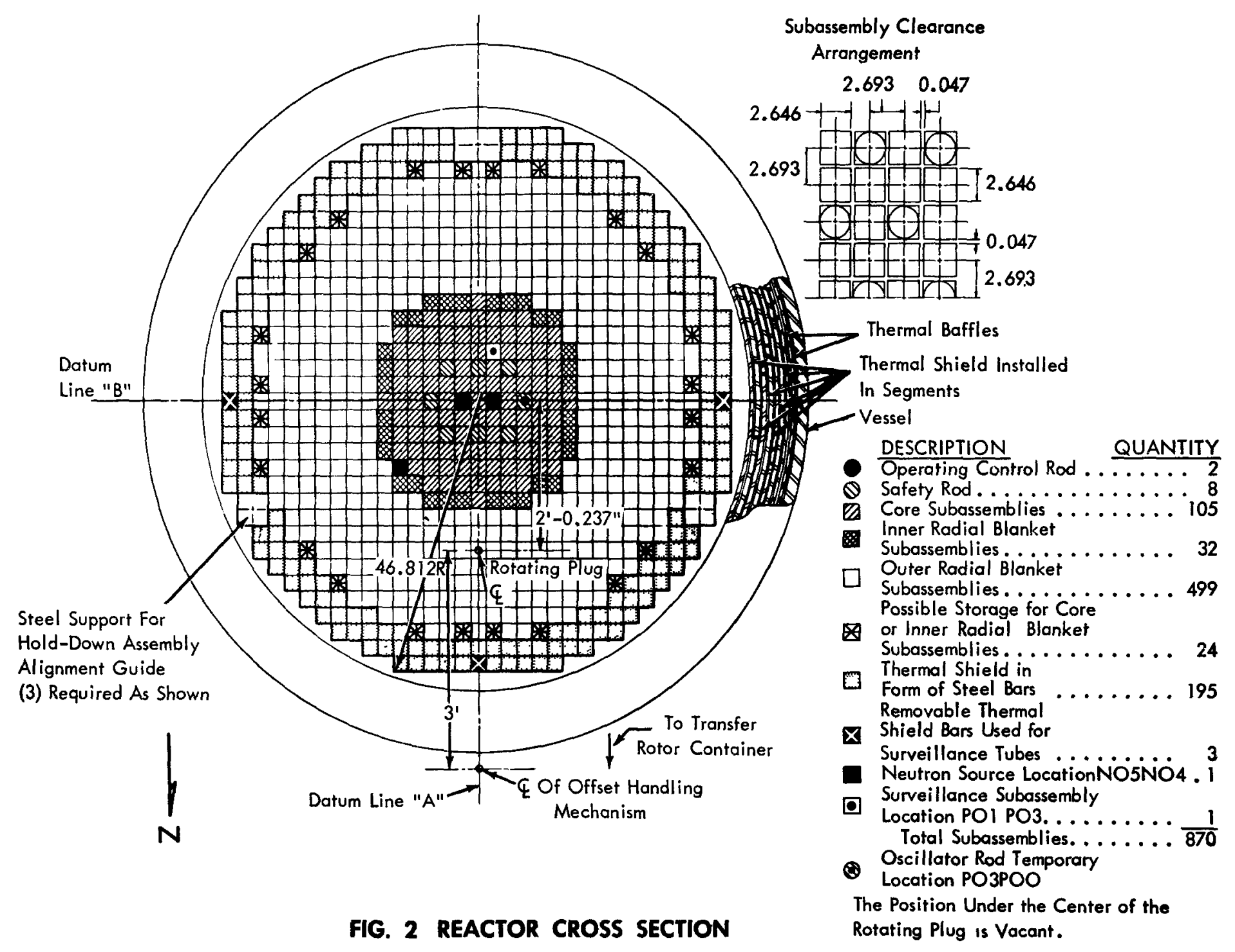


The major deviation from the standard geometric coordinate system is that the quadrants are designated by the letters $P$ for the positive sign and $\mathrm{N}$ for the negative. Each location is further identified by a set of twodigit numbers which indicate the distance from the axes. To identify a subassembly location in any quadrant, the number of subassembly spaces from the $Y$ axis is determined, and then the number of subassembly spaces from the $\mathrm{X}$ axis. The subassembly is then identified with the proper position; e.g., a fourth quadrant position would be Pl6-N05.

All lattice positions are supplied with sodium coolant flowing upward from a high-pressure plenum which is connected to the discharge lines of the three primary sodium pumps. The coolant flows upward through the individual core and inner radial blanket subassemblies into a large upper plenum; from there it flows by gravity to the three intermediate heat exchangers and then to the suction side of the primary pumps. Sodium also is used in the secondary cooling system. The outer radial blanket and shielding lattice positions are supplied with sodium coolant from the lowpressure plenum. The sodium from the low-pressure plenum, after cooling the blanket and thermal shield subassemblies, is mixed in the upper plenum with the sodium from the core before flowing to the intermediate heat exchangers.

The reactor is controlled by two operating control rods and seven safety rods; provisions have been included in the design for an eighth safety rod. The rods are of the poison type, containing boron carbide $\left(\mathrm{B}_{4} \mathrm{C}\right)$ in which the boron is enriched in boron-10. One operating control rod is for regulating purposes, the other for shimming. The average reactivity insertion rate of these rods is approximately one cent per second and one cent per minute, respectively. Both rods have approximate reactivity worths of 46 cents. The seven safety rods, which are spaced around the center of the core, provide shutdown reactivity. During operation of the reactor, the safety rods are held just above the axial blanket section of the core so that they can be rapidly inserted into the core if a scram becomes necessary. Each of the safety rods has a reactivity worth in excess of one dollar. Movement of the control and safety rods is actuated from the top. During fuel reloading, these rods are delatched from their drive extensions to allow them to remain in the core.

The neutron detectors (fission chambers and ion chambers) for normal reactor operation at power are located in six neutron-counter tubes (NCTs) embedded in the graphite neutron shield surrounding the reactor vessel (Figure 3). There are eleven channels of nuclear instrumentation distributed throughout the six neutron-counter tubes in a manner which will cover the full power range during reactor operation. The detectors located in these channels are designed to operate at temperatures up to $500 \mathrm{~F}$. 


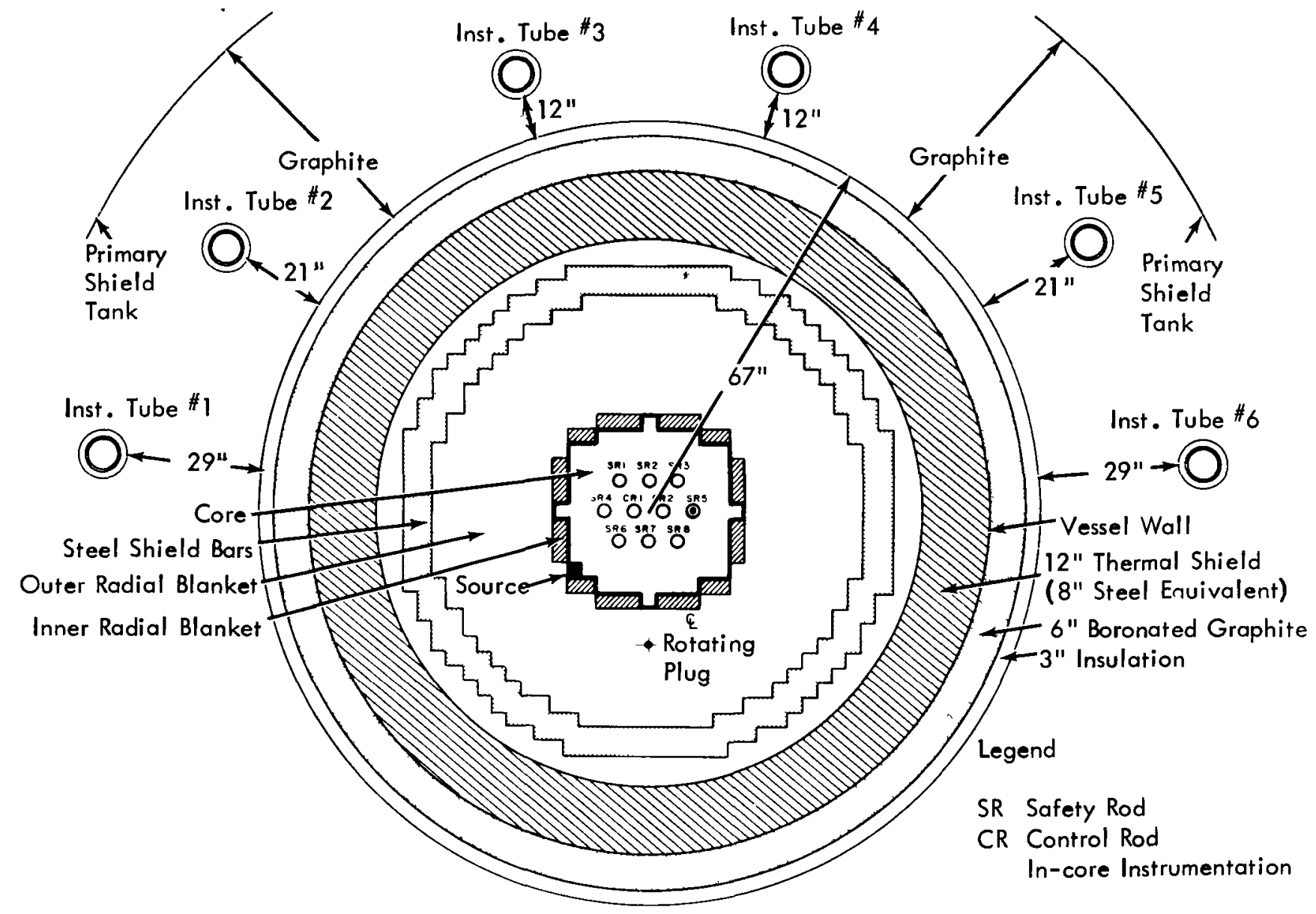

010768

FIG. 3 LOCATION OF NEUTRON-COUNTER TUBES IN GRAPHITE SHIELD 
An antimony-beryllium ( $\mathrm{Sb}-\mathrm{Be}$ ) neutron source is located in the reactor at the core-blanket interface (Figure 2) to provide a neutron flux at the neutron detectors during reactor start-up and to maintain a flux when the reactor is shut down. The radioactive antimony portion of the source is made as a separate piece for easy replacement and is in the form of a rod approximately 0.7 inch in diameter and 25 inches long. The radio-antimony rod fits inside a beryllium assembly, which is in the form of a hollow cylinder inside a stainless steel can having the external dimensions of a normal core subassembly fuel can. The handling head on the antimony section allows its insertion into and withdrawal from the beryllium by means of the normal fuel-handling mechanism. The beryllium portion must be installed and removed from the reactor through a special access port in the reactor vessel shield plug.

Additional information concerning the reactor design may be found in the Enrico Fermi Hazards Summary Report. 1

\section{B. REACTOR CORE AND BLANKET SUBASSEMBLIES}

\section{Core Subassemblies}

The core subassemblies used in the Enrico Fermi reactor consist of the outside wrapper tube, a 2.642-inch-square stainless steel tube having a nominal wall thickness of 0.096 inch. A combination handling head and holddown contact is attached to the top of the wrapper tube. To the bottom of the wrapper tube is attached a lower support section consisting of two concentric round tubes, the outer of which fits into the reactor vessel lower support plate. A spring between the outer and inner tubes allows for thermal expansion of the subassembly structure. A strainer at the inlet of each core subassembly is provided to prevent particles from lodging between the fuel pins.

The fuel region of each core subassembly is made up of 140 round $\mathrm{U}-10 \mathrm{w} / \mathrm{o}$ Mo alloy pins containing uranium enriched to $25.6 \% \mathrm{U}-235$. The nominal overall length of the pins is 32.75 inches; the outside diameter is 0.158 inch. Each pin is clad with a 5-mil thickness of reactor-grade zirconium metallurgically bonded to the periphery of the fuel alloy and is closed at the top and bottom with zirconium end caps. The lower end of each pin is fastened to a support structure by anchor bars inserted through slots in the bottom end caps and having upper ends free to accommodate changes in length resulting from temperature changes and growth due to radiation effects.

There are 17 support grids located at intervals along the length of fuel pins which serve as the support structure for the pins. The support structure holds 140 pins on a square pitch of 0.199 inch. The four corner 
positions are occupied by steel tie rods on which bear screws used to laterally restrain the fuel pin assembly within the subassembly wrapper tube.

The upper and lower axial blanket region in each core subassembly contains sixteen 0.395 -inch-diameter $U-3 \mathrm{w} / 0$ Mo alloy rods containing uranium depleted to $0.35 \%$ in $U-235$. The rods are enclosed in a $10-$ milthick stainless steel tube having an outside diameter of 0.443 inch. The radial clearance between the uranium alloy and the tube is filled with sodium to provide a bond with low thermal resistance and to allow for an increase in in diameter. Allowance for an increase in length of the alloy due to thermal expansion and radiation effects is provided inside the sealed tube by the sodium annulus and a gas space above the rod. A short stainless steel tube located within the gas space prevents the uranium from rising above the sodium.

The blanket rods are held in the subassembly and spaced around its periphery by lugged grids at the top and bottom of each axial blanket section. The center portions of the upper and lower axial blanket in each subassembly contain no blanket rod. Figure 4 is an isometric view of a core subassembly.

\section{Radial Blanket Subassemblies}

There are two types of blanket subassemblies, internally identical but differing in details of the support structure. In the inner radial blanket subassemblies, the nozzle contains a thermal expansion accommodation spring and the support structure is properly sized to fit the holes in the lower support plates that are intended for core and inner radial blanket subassemblies. The outer radial blanket subassemblies have a simple nozzle structure because, in the absence of a holddown plate, no special accommodation for thermal expansion is necessary. The nozzle for the outer radial blanket subassemblies is sized for the holes in this region of the lower support plates. These holes are smaller than those provided for core and inner radial blanket subassemblies; consequently, a core subassembly cannot accidentally be placed in an outer radial blanket position.

The radial blanket rods are the same as the axial blanket rods except that they are 71.5 inches long instead of 17 inches long and are wrapped with spiral wire. Further, the subassembly contains a complete lattice of 25 blanket rods supported by five parallel grids instead of the hollow lattice used in the axial blankets.

A removable orifice has been inserted into the lower support plate for each outer radial blanket position. An orifice also has been placed in the nozzle of each inner radial blanket subassembly. Figure 5 is an isometric view of a radial blanket subassembly. 


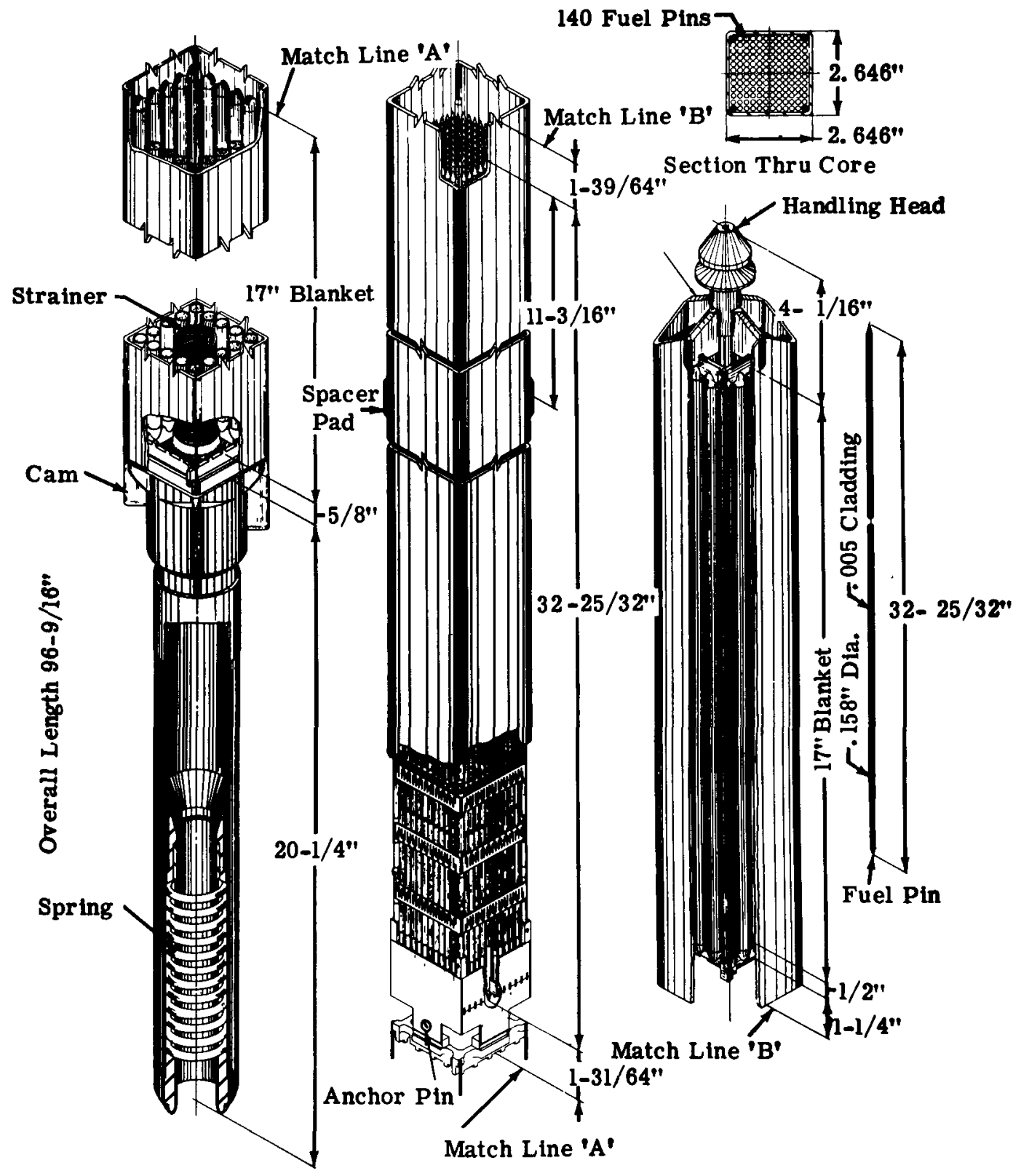




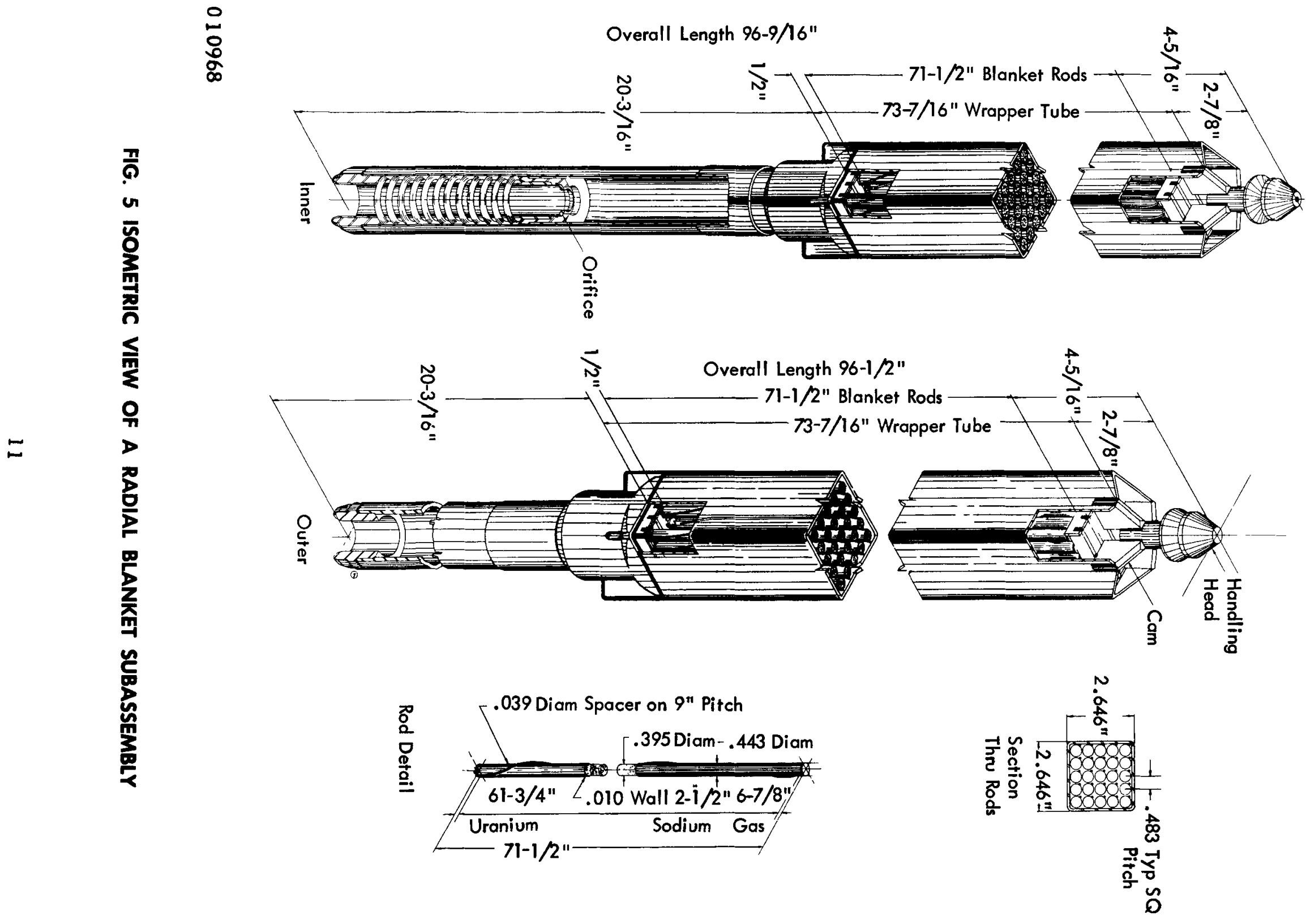


-

- 


\section{EXPERIMENTAL PROCEDURE}

\section{A. SPECTRUM FOIL PROGRAM}

Six foil materials were irradiated simultaneously at a number of elevations in eight lattice positions. After irradiation, the materials were removed from the reactor and their radioactive decay analyzed using a scintillation-counting system. The following sections describe the foils in detail, the equipment used to handle them, and the method and equipment used to analyze their radioactive decay.

\section{Description of Foils}

The following foil materials were irradiated during this program: manganese, nickel, gold, aluminum, iron, and thorium. The criteria for the choice of foil materials for irradiation were as follows:

a. The cross section should be fairly well known, preferably as a function of energy.

b. Foils should be compatible with $400 \mathrm{~F}$ temperature, a requirement which precluded the use of the usual candidates, S-32 and $\mathrm{P}-31$.

c. The half-life of the daughter should be of the order of hours or days. A required delay of approximately 7 hours between irradiation and counting due to fuel handling procedures, etc., precluded the use of short half-life reactions such as Al-27 $(\mathrm{n}, \mathrm{p})$.

The 0.250-inch-diameter, 0.100-inch-thick manganese foils were made from an alloy of $80 \%$ manganese and $20 \%$ copper; the copper content was required to overcome the brittleness of pure manganese so that the desired shape of the foil could be obtained. The 0.250-inch-diameter, 1-inchthick nickel foils were fabricated from Ni-200. The gold foils were 0.250 inch in diameter and 0.010 inch thick. The iron foils, made from $99.999 \%$ pure iron, were 0.197 inch in diameter and 1 inch long; iron foils of this diameter were chosen because of the availability of material. The 0.250inch-diameter, 0.100-inch-thick thorium foils were pure metal. The 0.250inch-diameter, 1 -inch-long aluminum foils were fabricated from XAP aluminum, a special high-purity form of aluminum fabricated by a powdered metallurgical process. Table 1 lists the foil materials and their dimensions, as well as the reaction and half-life of the daughter isotopes. 
TABLE 1 - FOILS FOR NEUTRON SPECTRUM PROGRAM

\begin{tabular}{|c|c|c|c|c|c|}
\hline Composition & Reaction & $\begin{array}{c}\text { of } \\
\text { Daughter }\end{array}$ & $\begin{array}{c}\text { Threshold, } \\
\text { Mev }\end{array}$ & $\begin{array}{l}\text { Length, } \\
\text { in. }\end{array}$ & $\begin{array}{c}\text { Diam, } \\
\text { in. }\end{array}$ \\
\hline $\mathrm{Mn}(80 \%)-\mathrm{Cu}(20 \%)$ & $M n-55(n, \gamma) M n-56$ & $2.58 \mathrm{hr}$ & - & 0.1 & 0.25 \\
\hline $\mathrm{Ni}-200$ & $\mathrm{Ni}-58(\mathrm{n}, \mathrm{p}) \mathrm{Co}-58$ & 71 days & 2.9 & 1.0 & 0.25 \\
\hline $\mathrm{Au}$ & $\mathrm{Au}-197(\mathrm{n}, \gamma) \mathrm{Au}-198$ & 2.7 days & - & 0.01 & 0.25 \\
\hline $\mathrm{Al}-\mathrm{XAP}$ & $\mathrm{A} 1-27(\mathrm{n}, \mathrm{a}) \mathrm{Na}-24$ & $15 \mathrm{hr}$ & 8.15 & 1.0 & 0.25 \\
\hline $\mathrm{Fe}(99.999 \%)$ & $\mathrm{Fe}-56(\mathrm{n}, \mathrm{p}) \mathrm{Mn}-56$ & $2.58 \mathrm{hr}$ & 7.5 & 1.0 & 0.197 \\
\hline Th & Th-232 (n, fission) & $\begin{array}{l}\text { fission } \\
\text { products }\end{array}$ & 1.64 & 0.1 & 0.25 \\
\hline
\end{tabular}

\section{Special Subas semblies}

Inasmuch as it was not possible to place foils in a normal Core $A$ fuel or blanket subassembly, it was necessary to design and build special subassemblies which allowed foils to be located within the reactor core and blanket without creating the possibility of loss of the foils or distortion of the nuclear characteristics of the reactor. These special subassemblies, which were constructed for the U-235 and U-238 foil program ${ }^{2}$ conducted earlier in the Fermi reactor, are described below.

\section{a. Core Foil Subassembly}

The two core foil subassemblies differ from a normal core subassembly in that the four centrally located pins in the fuel section of each subassembly were removed and replaced by a square sheath. This sheath was fastened at the same place the fuel pins were fastened and extended to just below the bottom of the handling head. The handling head was hollow and had a cap which could be unscrewed to allow insertion or removal of foils from the sheath. Figure 6 shows the details of a normal fuel subassembly and a core foil subas sembly.

\section{b. Blanket Foil Subassembly}

The two blanket foil subassemblies were identical with normal radial blanket subassemblies* with the exception that the central blanket pin

* There were no ir radiations in the inner radial blanket subassemblies. 


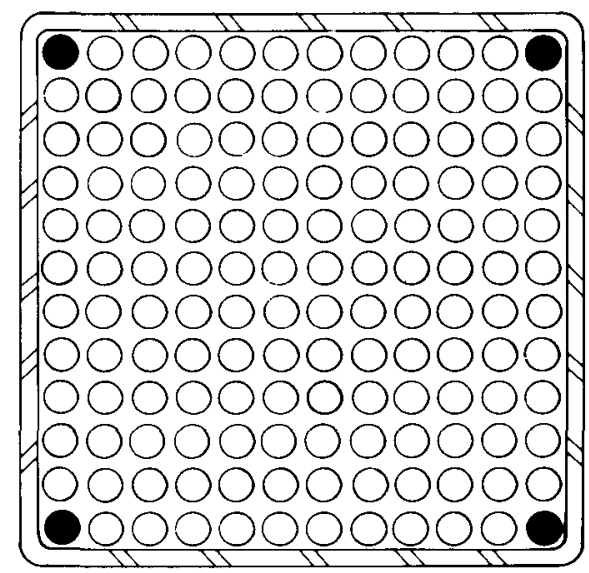

Core Fuel Subassembly

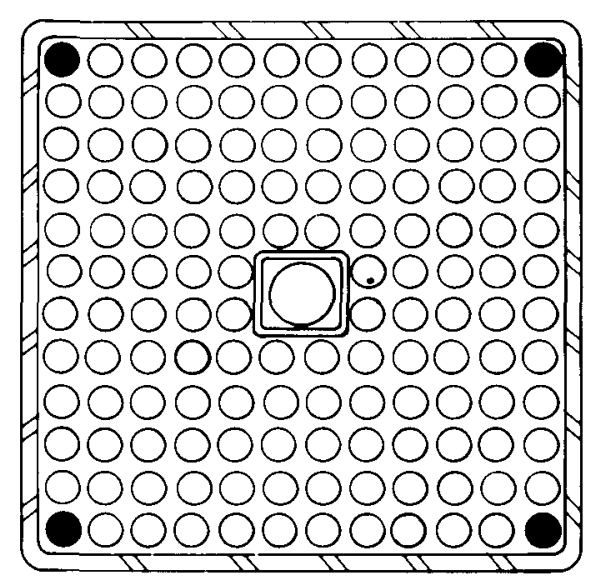

Core Foil Subassembly

Showing Foil Tube 
of each subassembly was replaced by a tube which extended to just below the handling head of the subassembly. This tube contained a plug so that the effective length of the tube in the blanket foil subassembly was the same as the effective length of the sheath in the core foil subassembly. As in the core foil subassemblies, the handling head was hollow and capped by a threaded plug which could be removed to allow the insertion and removal of foil specimens.

The two core and two blanket foil subassemblies were designed to be used as normal subassemblies following the test program.

\section{Counting Equipment}

There were no provisions for dissolving the foil samples and performing absolute counting, and most of the half-lives involved were too short to have foils sent to outside laboratories for such counting. Thus, all count rates were obtained with a scintillation detector. Figure 7 is a flow diagram of the scintillation detector and other equipment used in this test program. The specific equipment ${ }^{*}$ is listed and described below:

\section{a. Scintillation Detector}

The scintillation detector was a Hamner Electronics Company A-18 consisting of a $2 \times 2$ NaI (T1) crystal optically coupled to an RCA 6432 -A photomultiplier tube enclosed in a housing containing an integral preamplifier.

\section{b. Linear Amplifier and Pulse Height Analyzer}

The linear amplifier was a Hamner Electronics Company Type N-302 amplifier having a gain of 10,000 with single delay line clipping, a rise time of less than 0.2 microsecond, and a linearity of better than $0.2 \%$ over the range of 0 to 100 volts. The pulse height analyzer section could be operated in either differential or integral mode by means of a switch located on the front panel.

\section{c. High Voltage Supply}

The high-voltage supply, a Model 412A manufactured by the John Fluke Manufacturing Co., had an output voltage range of 500 to 2000 volts and a stability rating of $0.01 \%$ for a $10 \%$ line change. In addition to the regulation provided by the high voltage supply, a Solar transformer was

* Two channels of counting equipment were available for use; however, all the results reported herein were obtained using the channel designated "B". 


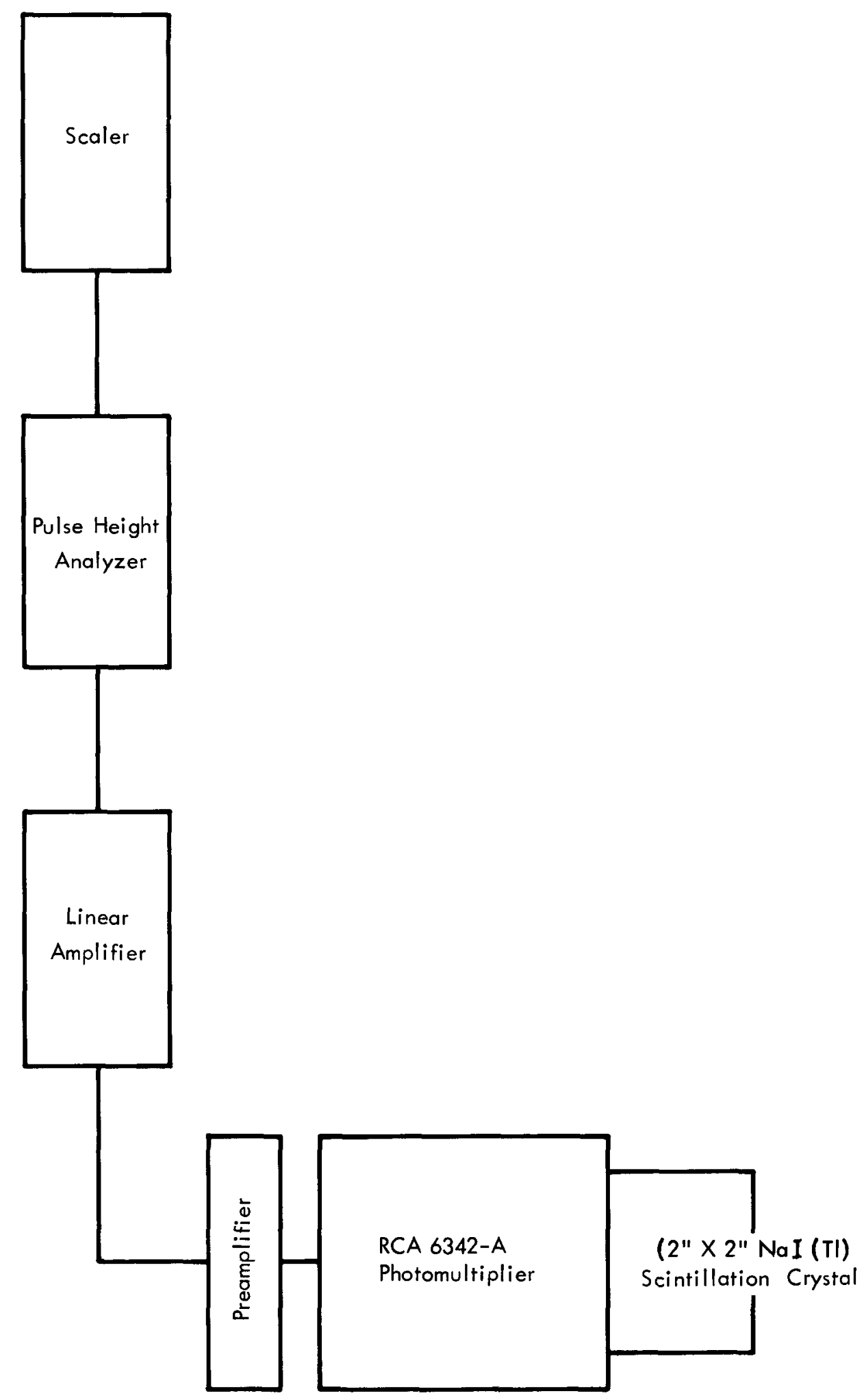

011168

FIG. 7 BLOCK DIAGRAM OF SCINTILLATION COUNTING EQUIPMENT 
used to provide additional stability for the high voltage to the phototube and the voltage to the linear amplifier.

\section{d. Scaler}

The scaler was an RIDL Mode1 49-25 having three electronic decades and four mechanical decades. The resolving time of the electronic decades was $I \mu$ sec and the input limitation to the mechanical register was 20 counts per second, resulting in an overall input frequency limitation of 20,000 counts per second.

\section{e. Shield}

The shield was similar to the Technical Associates Type LS-66 lead shield, which allowed the scintillation detector to be mounted vertically. The shield contained a stand for holding the sample tray at varying highly reproducible distances from the scintillation crystal. A planchet was used with the sample tray to provide accurate positioning of the foil within the sample tray.

\section{Other Equipment}

\section{a. Foil Tubes and Spacers}

To prevent sodium from coming into contact with the foils during their irradiation, the foils were put into stainless steel tubes which were welded closed before being inserted into a foil subassembly. To maintain the proper elevation of the foils in the foil tubes, aluminum spacers were inserted between each foil as it was being loaded into a foil tube.

The foil tubes were made from Type 304 stainless steel tubing having inside and outside diameters of 0.266 inch and 0.312 inch respectively. The 54-inch-long tubes were closed at the bottom by a 3/8inch-long stainless steel plug which was welded in place. After loading, the foil tubes were closed at the top by brazing in place a cap which served both to close off the tube and to provide a convenient means of retrieving the foil tube from the foil subassembly after irradiation. This system necessitated breaking the end cap weld for removal of the foils.

The spacers used to maintain the elevation of the foils within the foil tubes were made of 0.250 -inch-diameter Type 1100 aluminum rod, cut to the proper length and manually filed to within \pm 0.001 inch of its nominal length. 


\section{b. Glove Box}

To permit foil tubes to be inserted into and removed from the foil subassemblies without allowing air to come in contact with residual sodium clinging to the subassemblies, such transfers were made in a glove box located in the cask car maintenance pit of the Fuel and Repair Building (FARB) at a level which afforded convenient access to the gloves by a man standing in the pit. A valve was supported on the top of the glove box by a thimble piece at the proper elevation to allow its mating with the seal flange of the cask car. Figure 8 is an illustration of the glove box, its installation, and manner of use.

Tools were available in the glove box to facilitate the removal of the cap from the foil subassembly handling head and removal of the foil tubes from the subassemblies. Foil tubes were placed in and removed from the glove box by means of an air lock which was located 180 degrees from the viewing glass and gloves. An insulated, induction-heated tube formed the lower section of the glove box assembly. This tube was used to maintain an inert atmosphere around the subassembly during foil tube exchanges. The lower section of the glove box assembly was heated to prevent freezing of the sodium on the subassemblies and of the sodium bonding of the upper and lower axial bla $\mathrm{nket}$ pins in the core foil subassemblies. Had the sodium frozen, the subassemblies would not have been usable under full power conditions because of the possibility of a nonbonded area being created by the freezing and remelting of the sodium bond. Such a nonbond in a blanket pin could have led to a hot spot and possible melting of the blanket pin. Refreezing of the sodium bond in the blanket foil subassemblies was not considered to be a problem because it was not intended that these subassemblies would be used at full power. Argon gas supplied from the FARB argon header was used as the inert gas in the glove box.

\section{c. Temporary Instrument Thimble}

A temporary instrument thimble (TIT) was used during these tests to provide direct access to the reactor core where the preliminary foil irradiation was made and where the absolute fission counters were positioned. The TIT occupied position P03-P00, which was designed as a safety rod position. The TIT, a gastight stainless steel tube sealed at the lower end, penetrates the reactor rotating plug, extends downward through the core, and bottoms against the lower guide tube dashpot. For the foil irradiations, an aluminum foil holder was used to locate the foils in the TIT; the foils were placed into recesses in the TIT foil holder. At the end of the irradiation, the foil holder was removed from the TIT and the foils removed from the holder. 


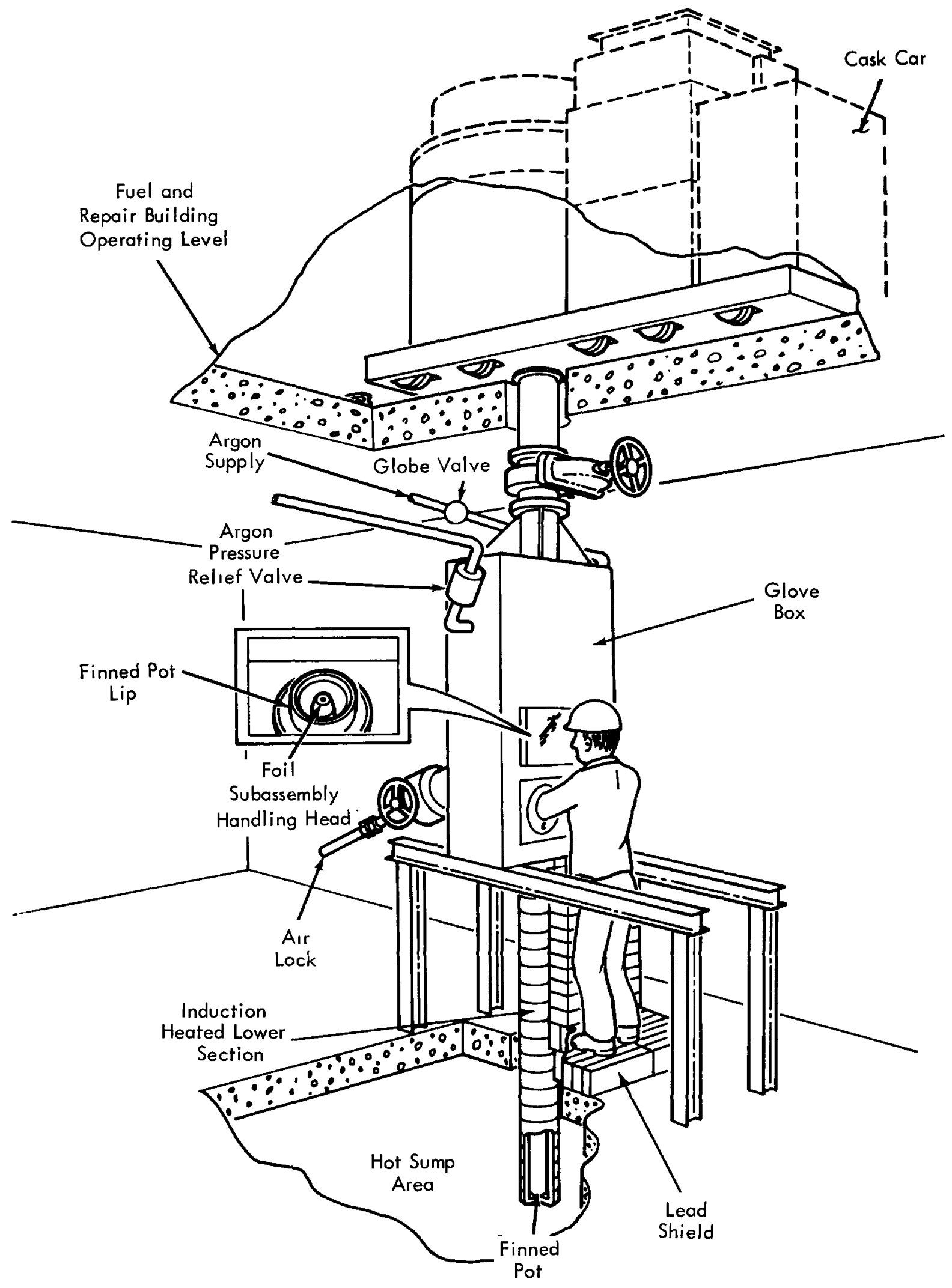

011268

FIG. 8 GLOVE BOX INSTALLATION 


\section{d. BF $3_{3}$ and Fission Counter Power-Monitoring Channels}

The method used for power normalization between irradiations involved the use of the integrated counts accumulated on two neutron detector channels during the irradiation: one channel consisted of $\mathrm{BF}_{3}$ located in NCT 3; the other channel, a fission counter located in NCT 4.

The electronics of the two channels was identical and consisted of a preamplifier, amplifier, discriminator, and scaler. The elevation of the neutron detectors in the guide tube was adjusted so as to obtain a count rate of $2500 \mathrm{cpm}$ at $10 \mathrm{kw}$. This resulted in a total integrated count of $6 \times 10^{6}$ for a one-hour irradiation at the highest power level used. This value is within the total count capacity of $1 \times 10^{7}$ for the scalers which were used.

\section{Locations of Irradiations}

Foils were irradiated in nine reactor lattice locations: four in the core, four in the blanket, and one in the TIT. The eight lattice positions were covered in five separate irradiations of one hour's duration. The irradiation in the TIT was a preliminary irradiation to verify reactor power level requirements and develop the analysis procedures for the irradiated foils. The remaining irradiations were done using the core and blanket foil subassemblies to locate the foils in the lattice. The lattice positions at which foils were located are illustrated in Figure 9.

Of the six foil materials irradiated in the foil subassemblies, aluminum, nickel, and gold were irradiated at nine elevations in each lattice position; thorium and manganese, at eight elevations; iron, at seven elevations.

\section{Determination of Foil Activity}

\section{a. Calibration of Counting Equipment}

The counting equipment was calibrated to establish the relationship between output of the linear amplifier in volts and the energy of gamma rays in electron volts. For the sake of simplicity, the gain of the scintillation counting system was adjusted so that the gamma ray energy of cesium-137 (0.662 M ev) resulted in a pulse of 66.2 volts from the linear amplifier. Large gain adjustments were accomplished by changing the gain setting of the linear amplifier; smaller gain changes, by varying the high voltage to the photomultiplier tube.

With the gain of the system adjusted to give an output pulse from the amplifier of 66.2 volts for a $0.662-\mathrm{Mev}$ gamma ray, other sources having known gamma-ray energies were checked to verify the linearity of 


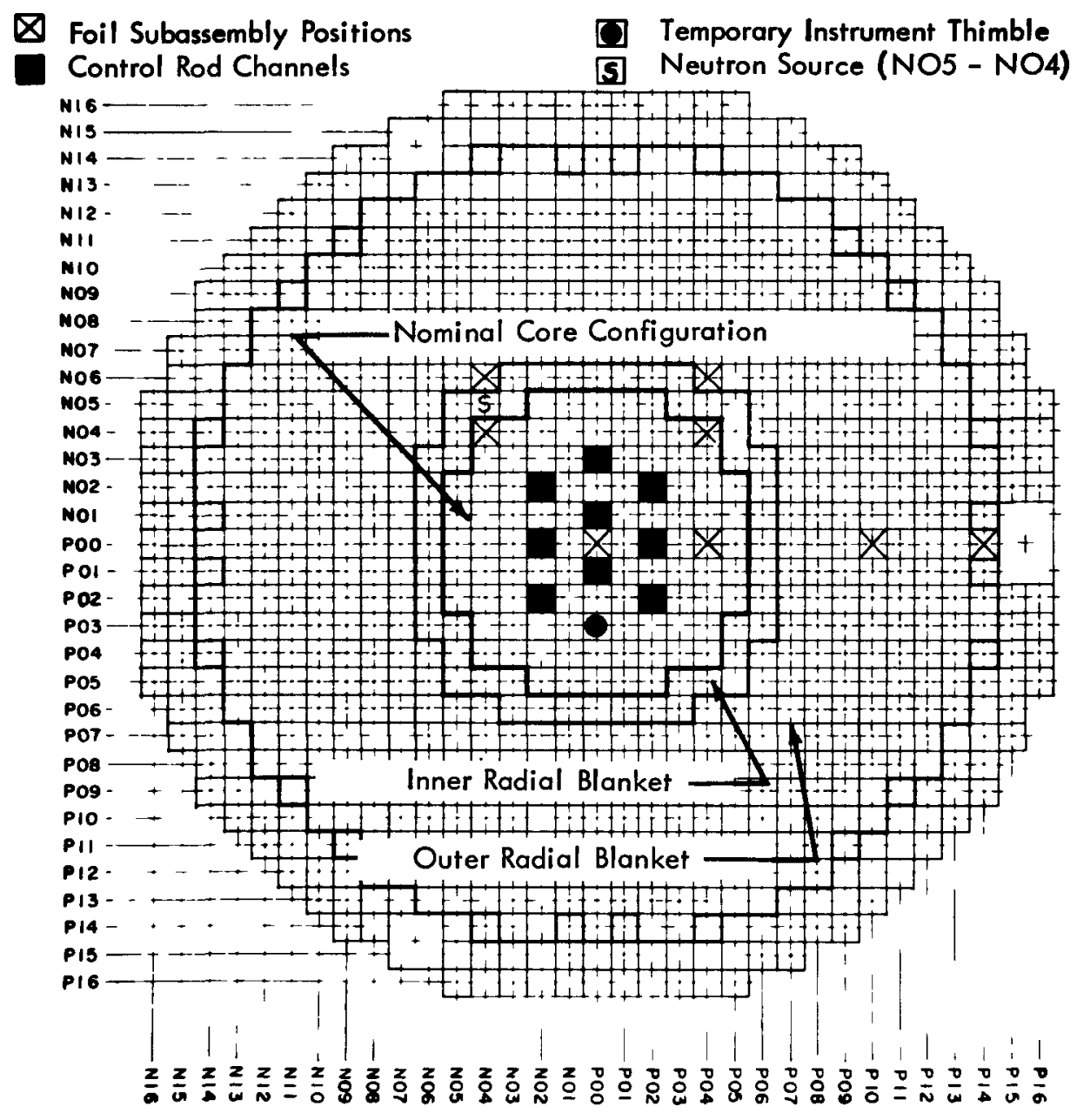


the system and the slope of the gamma ray energy versus amplifier output voltage curve. The isotopes used for this purpose and the energy of their gamma rays are listed in Table 2. The results of the linearity determination are illustrated in Figure 10.

TABLE 2 - CALIBRATION ISOTOPES

\begin{tabular}{ll} 
Isotope & $\begin{array}{c}\text { Gamma } \begin{array}{l}\text { Ray Energy, } \\
\text { Mev }\end{array} \\
\text { U-235 }\end{array}$ \\
\cline { 2 - 2 } $\mathrm{Ba}-133$ & 0.096 \\
$\mathrm{Cs}-137$ & 0.195 \\
$\mathrm{Co}-60$ & 0.36 \\
& 0.662 \\
& 1.17 \\
& 1.33
\end{tabular}

Note: The resolution of the counting equipment for Cs -137 gamma rays was measured to be $7.4 \%$.

\section{b. Gain Stability}

To allow the comparison of the count rate observed on foils which were counted at significantly different times, it was necessary that the gain of the counting equipment be reproducible.

The equipment was initially calibrated to determine the standard activity of the Cs-137 source above $662 \mathrm{kev}$. To allow the gain of the counting equipment to be returned with a high precision to a standard value, the total activity above $662 \mathrm{kev}$ ( 66.2 volt pulse height) of this source was meas ured approximately every half hour during the time periods over which foils were counted.* Since this base line lies at the peak of the pulse height distribution (Fig. 11), a small change in system gain would result in a relatively large change in Cs-137 counting rate, thus providing a sensitive measure of gain drift. When the activity observed during a gain check differed from the standard source count rate by more than a specified amount, the system gain was adjusted by changing the high voltage to the photomultiplier tube until the standard counting rate was again observed. The observed relationship between count rate and change in the high voltage is shown in Fig. 12. It can be seen that an increase in high voltage of 1 volt (nominal

* Decay of the 30-year half life standard source was taken into account where appropriate, since the time between some of the foil irradiations approached one year. 


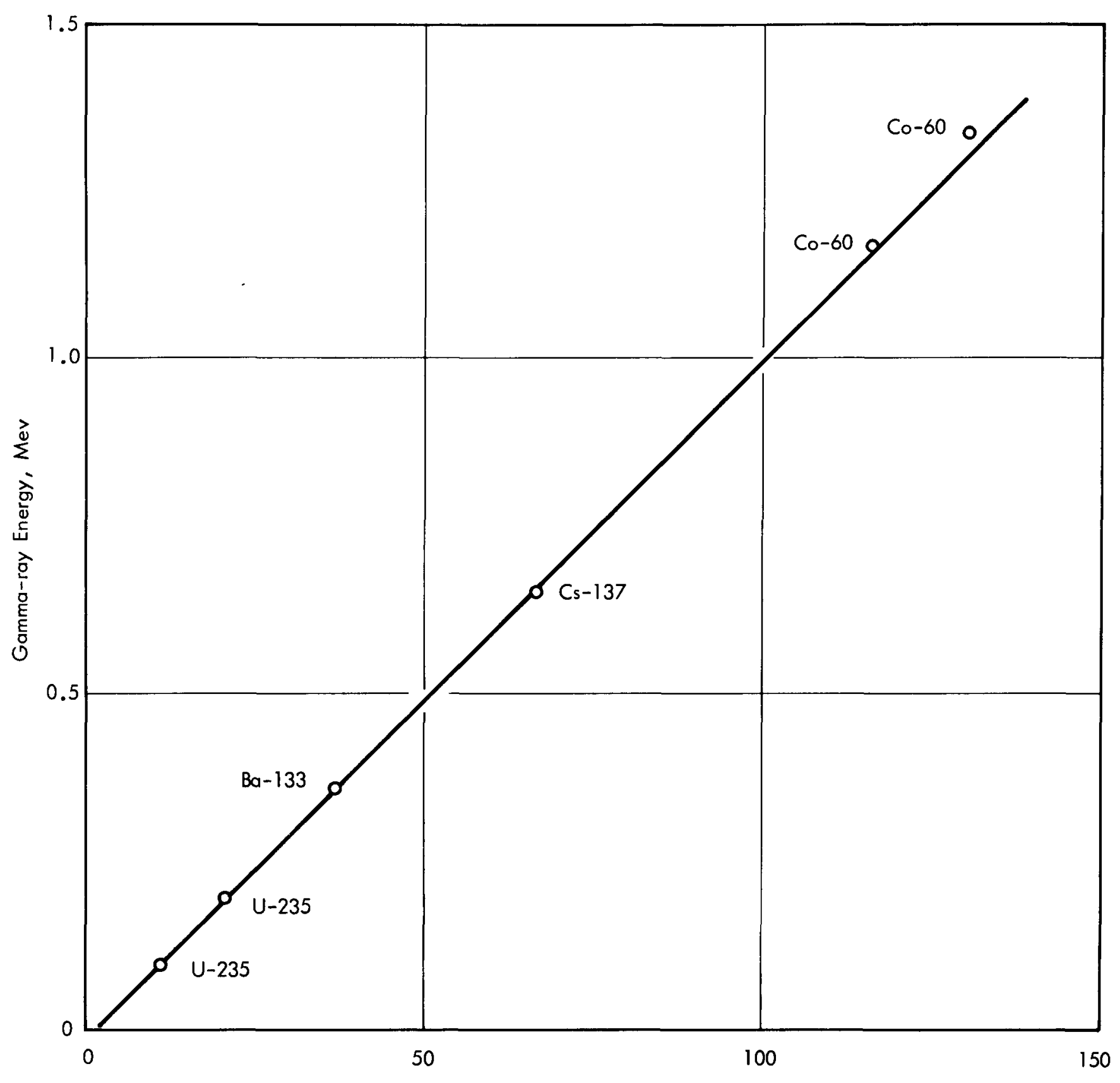

Linear Amplifier Output, Volts

011468

FIG. 10 GAMMA-RAY ENERGY AS A FUNCTION OF LINEAR AMPLIFIER OUTPUT 


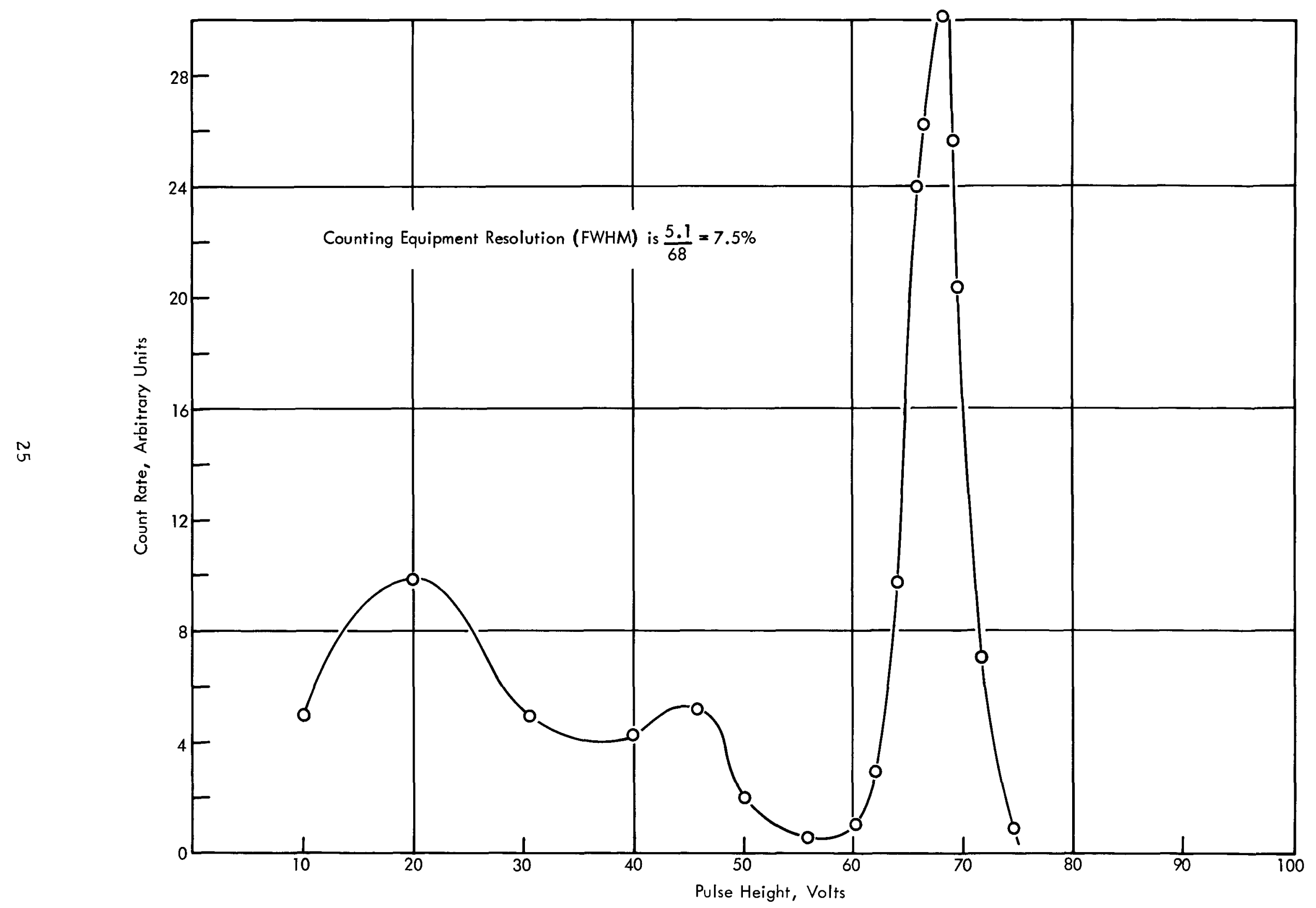


high voltage to the photomultiplier tube was 1000 volts) results in a change in count rate of approximately 12 per cent. For the entire course of the experiment the total range covered by high-voltage corrections to the gain was 7 volts, which corresponds to a gain range of 5 per cent.

\section{c. Measurement of Foil Activity}

To establish the low-energy cutoff level of the pulse height analyzer to be used for the analysis of each of the six foil materials, a pulse height analysis was made of the materials after a preliminary irradiation in the TIT. Figures 13 through 16 illustrate the results of these pulse height analyses. Also indicated in each of these figures is the value used for the low-energy cutoff. All six materials were analyzed in such a manner that all pulses above the low-energy cutoff were counted.

To verify that only pulses originating from the desired reaction product were being counted, each foil material (except thorium) irradiated during the preliminary irradiation was counted as a function of time, using the low-energy cutoff level determined for each foil type. Figures 17, 18, 19, 20, and 21 give the resulting decay curves. These figures indicate the agreement between the measured value of the half-life and the value obtained from literature.

The activity of foils irradiated in lattice positions was measured on the top shelf of the counting geometry, with the exception of the gold foils, which were analyzed while located on the bottom shelf of the counting geometry. This was necessary to reduce the system counting rate to a level which would not saturate the counting equipment.

\section{Normalization of Reactor Power}

To allow the comparison of results obtained among foils which were irradiated at different reactor power levels, it was necessary to adjust all results to a common power level.

Two channels (channel 3 and channel A) of neutron-counting equipment and a Keithley micromicroammeter were available for this purpose. These neutron monitoring channels were started at the beginning of the irradiation and allowed to continue to accumulate counts the entire length of an irradiation. In theory, the number of counts accumulated during this time should be directly proportional to the integrated power of the irradiation. In practice, however, it was necessary to make some adjustments to the integrated counts to correct for obvious anomalies of uncertain origin (i.e., voltage variation, amplifier gain, power drift, etc.).

The accumulated counts obtained on the two neutron-counting channels are shown in Table 3 , along with the average Keithley reading obtained for each irradiation. Also given in Table 3 are three types of 


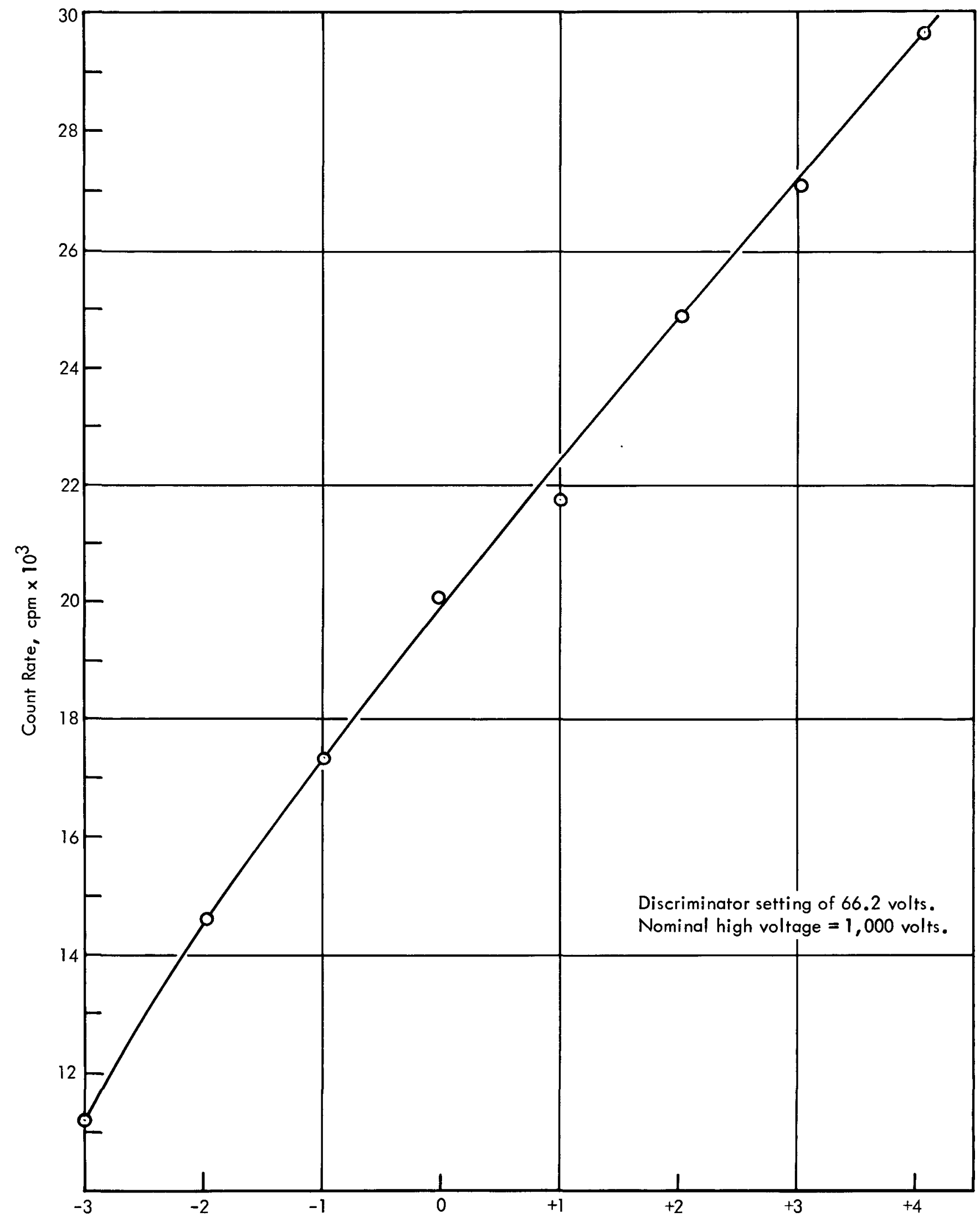

011668

High Voltage Deviation, Volts

FIG. 12 INTEGRAL Cs-137 COUNT RATE AS A FUNCTION OF HIGH-VOLTAGE DEVIATION FROM THAT REQUIRED TO OBTAIN STANDARD SYSTEM GAIN 


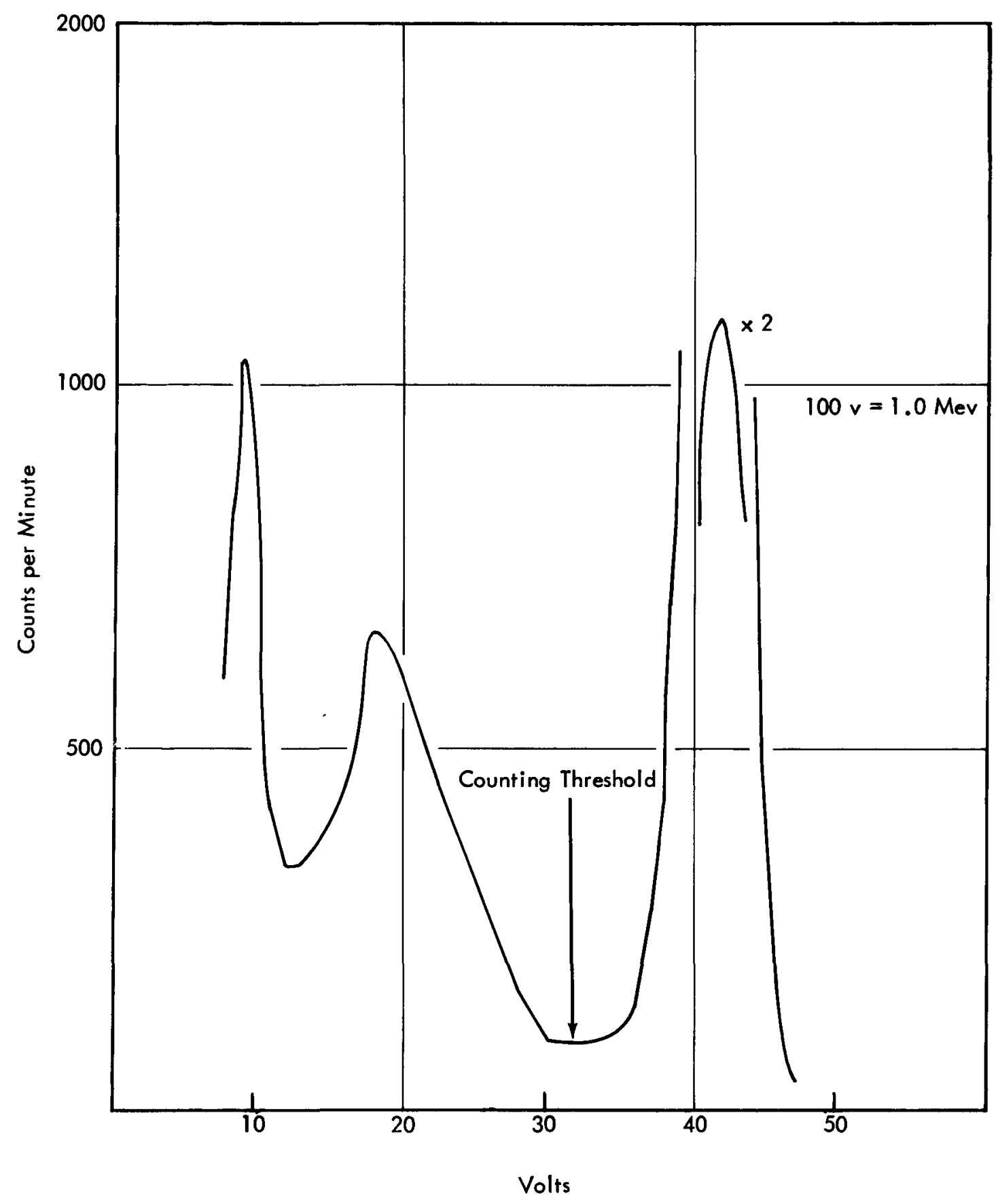

011768

FIG. 13 PULSE HEIGHT ANALYSIS OF IRRADIATED GOLD FOIL 


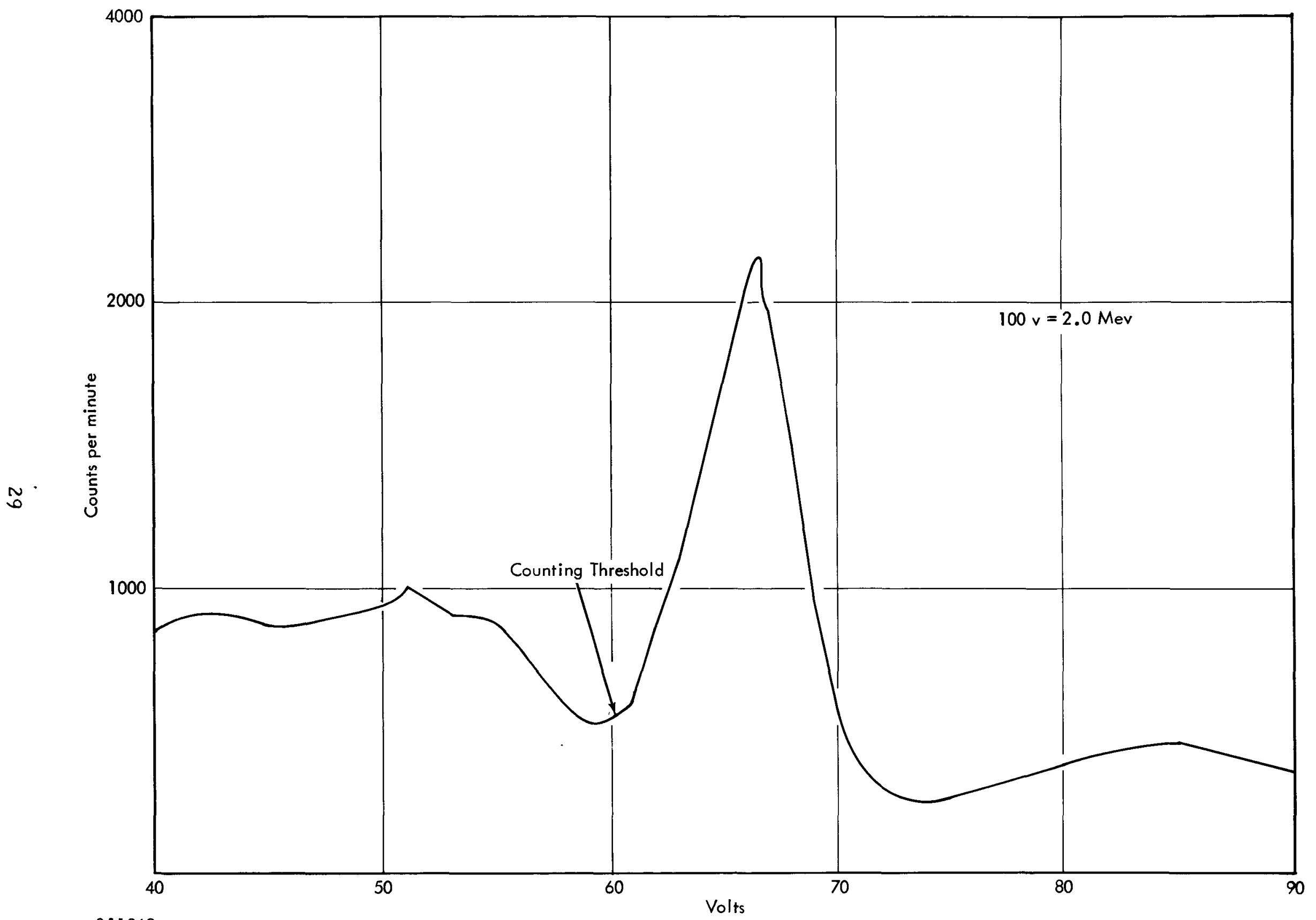

011868

FIG. 14 PULSE HEIGHT ANALYSIS OF IRRADIATED ALUMINUM FOIL 


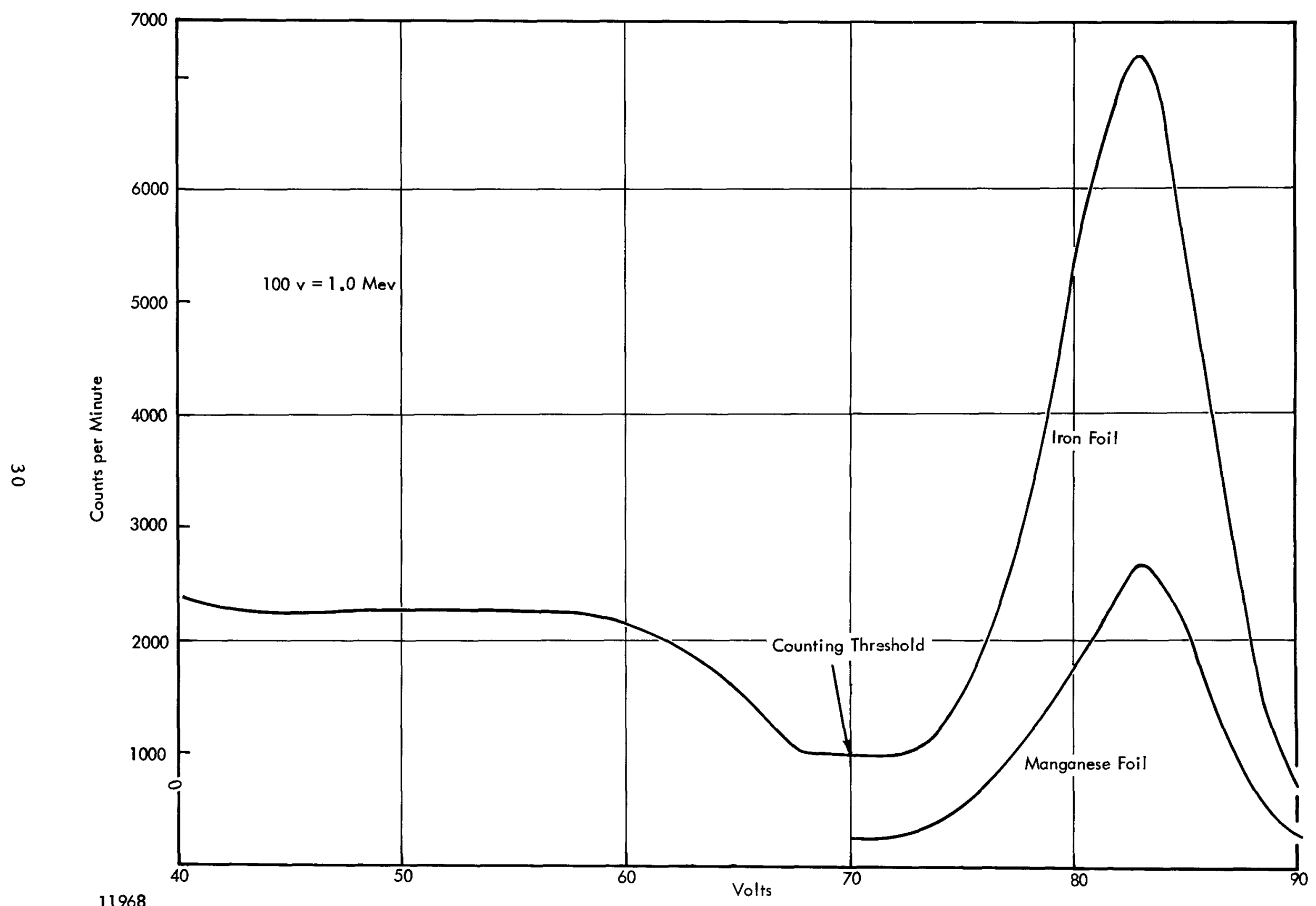




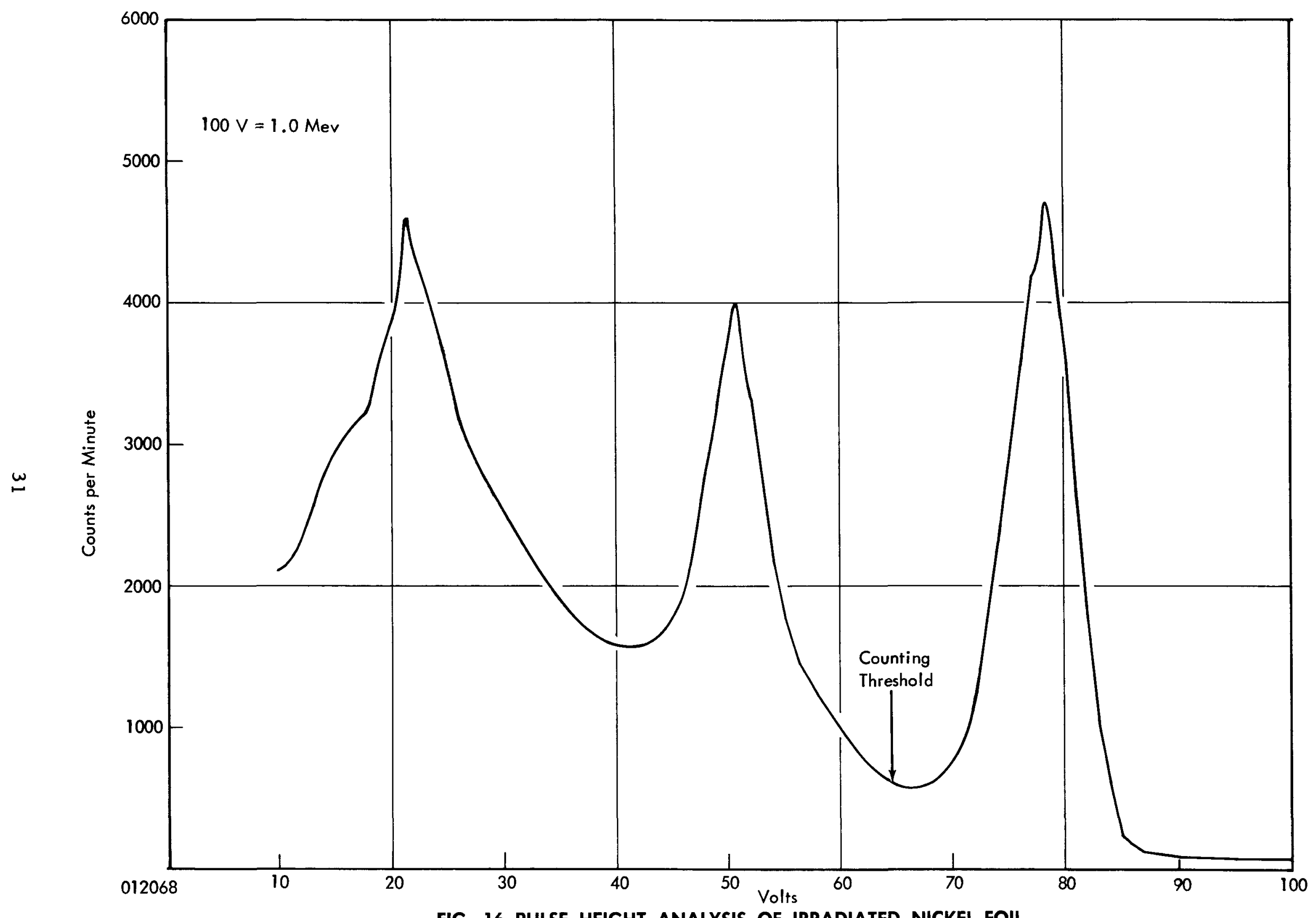

FIG. 16 PULSE HEIGHT ANALYSIS OF IRRADIATED NICKEL FOIL 


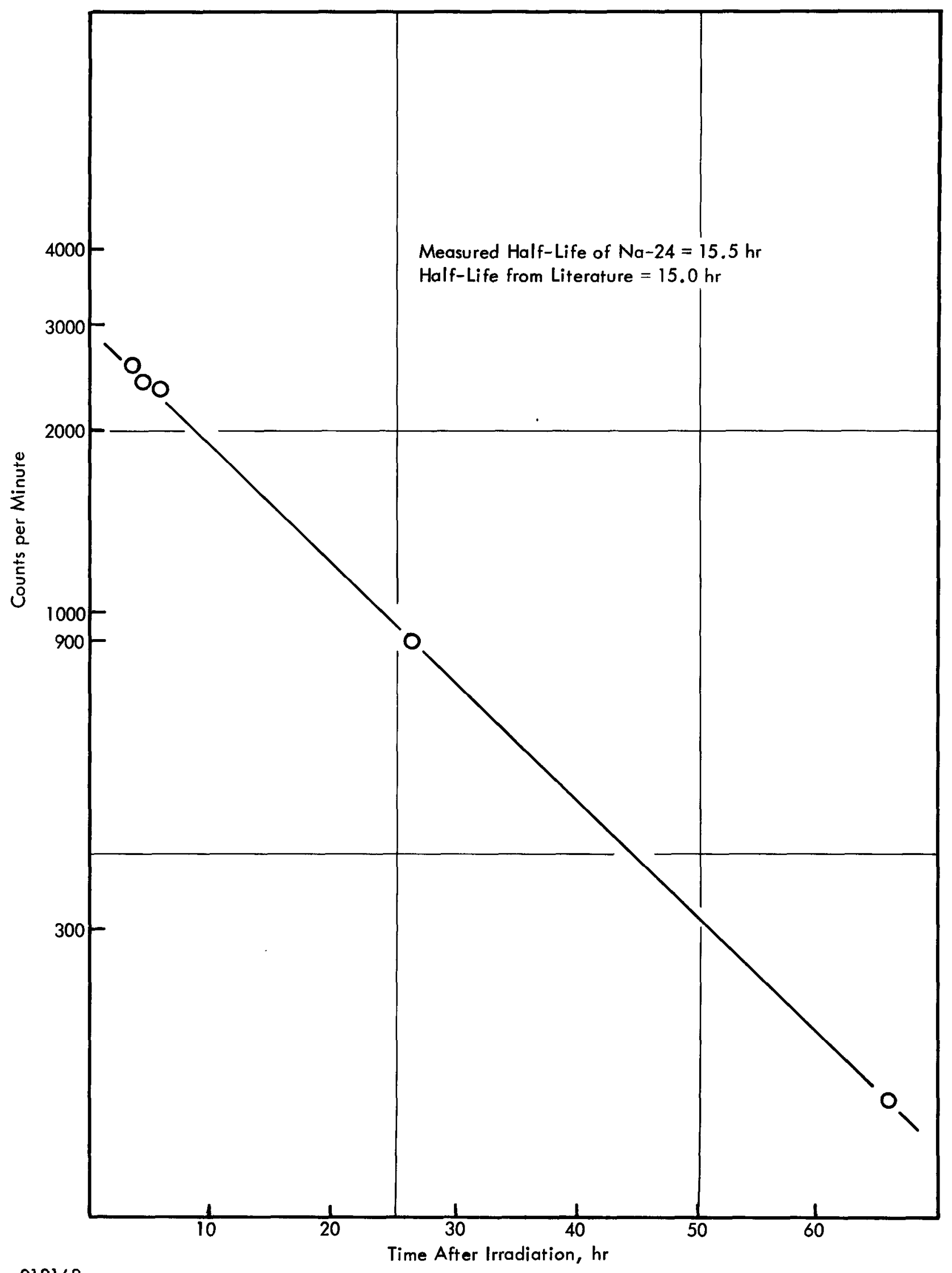

012168

FIG. 17 HALF-LIFE DETERMINATION OF ALUMINUM FOIL 


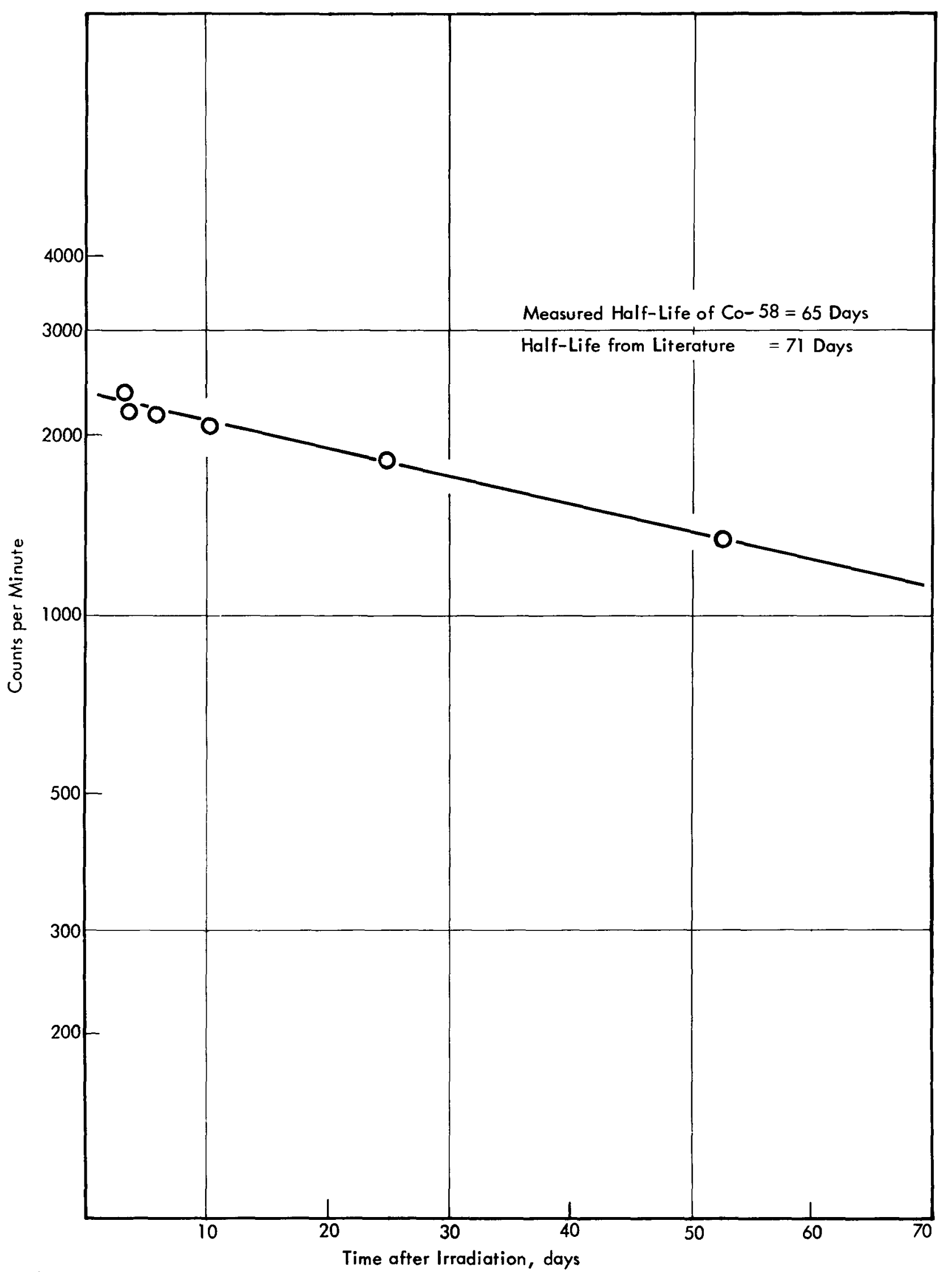

012368

FIG. 18 HALF-LIFE DETERMINATION OF NICKEL FOIL 


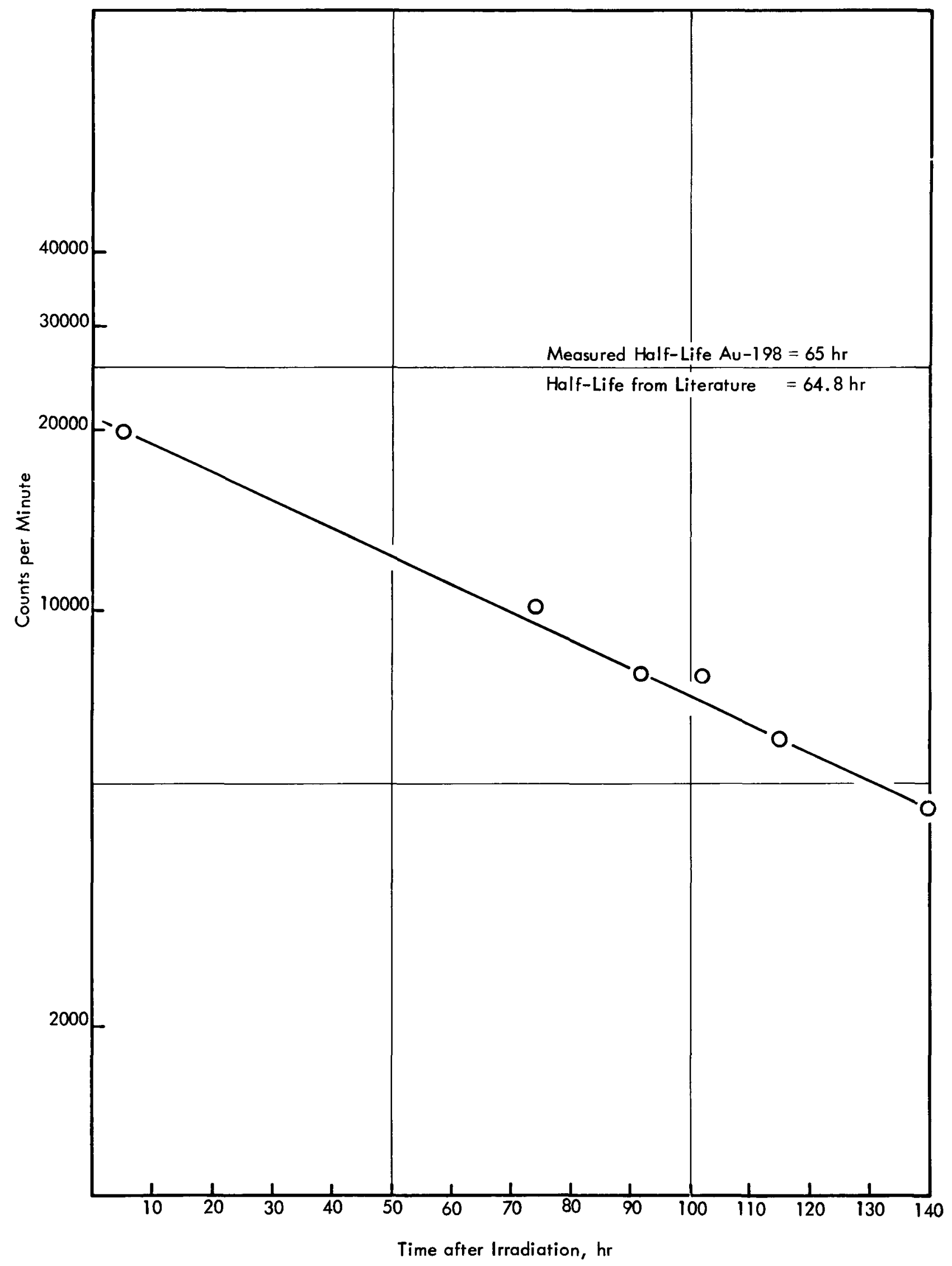

012268

FIG. 19 HALF-LIFE DETERMINATION OF GOLD FOIL 


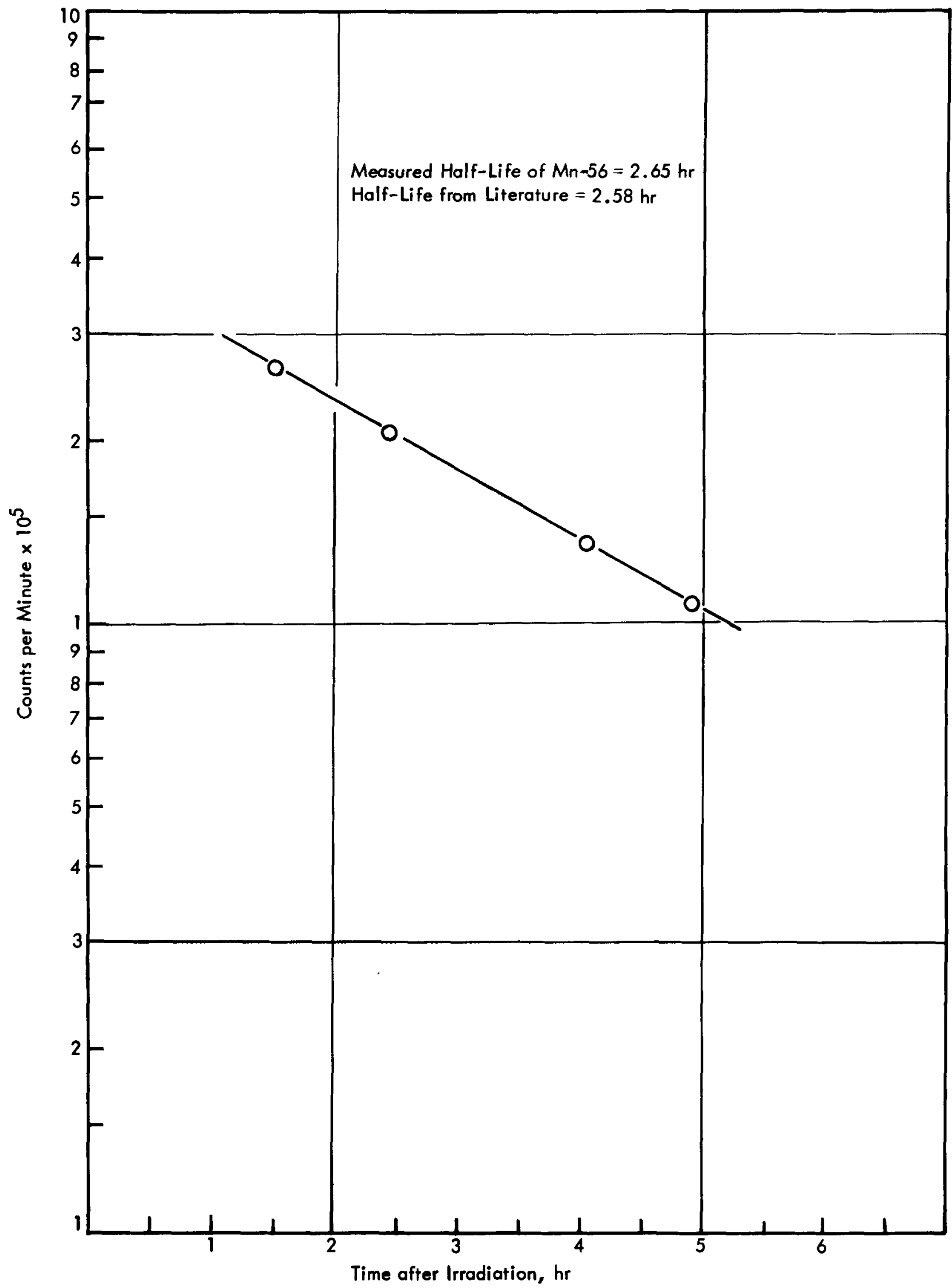

012468

FIG. 20 HALF-LIFE DETERMINATION OF IRON FOIL 


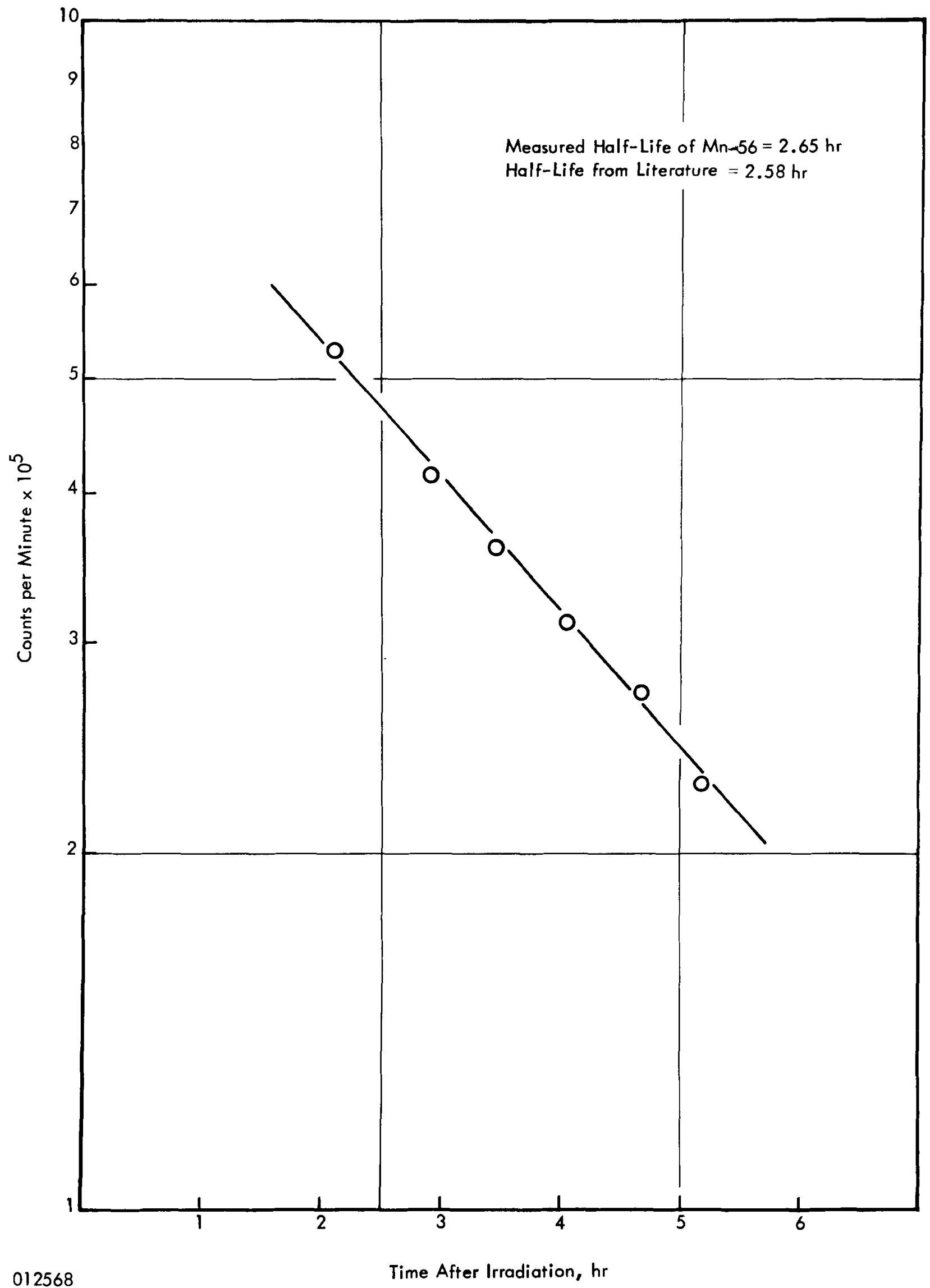

FIG. 21 HALF-LIFE DETERMINATION OF MANGANESE FOIL 
TABLE 3 - INTEGRATED COUNTS, CURRENTS, AND RATIOS OBTAINED FOR POWER NORMALIZATION

\begin{tabular}{|c|c|c|c|c|c|c|}
\hline \multirow[b]{2}{*}{$\begin{array}{l}\text { Irradia- } \\
\text { tion No. }\end{array}$} & \multicolumn{2}{|c|}{ Integrated Counts } & \multirow[b]{2}{*}{$\begin{array}{l}\text { Keithley } \\
\text { Current } \\
\end{array}$} & \multicolumn{3}{|c|}{ Ratio of Channels } \\
\hline & $\begin{array}{c}\text { Channel } \\
3 \\
\end{array}$ & $\begin{array}{c}\text { Channel } \\
\mathrm{A} \\
\end{array}$ & & $K / 3 \times 10^{-13}$ & $\mathrm{~K} / \mathrm{A} \times 10^{-13}$ & $\mathrm{~A} / 3$ \\
\hline$S-4$ & 159,831 & 101,661 & $0.553 \times 10^{-7}$ & 3.46 & 5.45 & 0.635 \\
\hline$S-5$ & 755,138 & 486,835 & $0.266 \times 10^{-6}$ & 3.52 & 5.46 & 0.645 \\
\hline$S-6$ & $6,336,565$ & $4,136,000$ & $0.299 \times 10^{-5}$ & 3.60 & 5.52 & 0.654 \\
\hline$S-7$ & 39,776 & 23,811 & $0.133 \times 10^{-7}$ & 3.36 & 5.60 & 0.598 \\
\hline$S-8$ & 83,012 & 53,040 & $0.298 \times 10^{-7}$ & 3.58 & 5.60 & 0.640 \\
\hline
\end{tabular}

ratios for each irradiation. These are: (1) the ratio of the average Keithley reading to the integrated count on channel 3 ; $(2)$ the ratio of the average Keithley reading to the integrated count on channel $A$; and (3) the ratio of the integrated count on channel A to that on channel 3. If there were no irregular ities in the method, each ratio would have a constant value for all irradiations, but they do not. In an attempt to obtain the best value for use in power normalization, the counts observed on channels 3 and $A$ and the observed current from the Keithley micromicroammeter were empirically adjusted with the aid of additional irradiation and power-monitoring data to bring each of the three ratios for each irradiation as close as possible to the average value obtained during all irradiations. The adjusted counts and current values are given in Table 4. For the purpose of power normalization, the adjusted values for the channel-3 count rate were used because they were least affected.

\section{TABLE 4 - ADJUSTED COUNTS AND CURRENTS AND ADJUSTMENT} FACTORS USED FOR POWER NORMALIZATION

Adjusted

Integrated Count

Ir radiation

No.

$S-4$

Channel 3

160,000

755,140

S-5

S-6

$6,352,000$

S-7

38,400

S-8

82,000
Channel A

103,000

487,000

$4,100,000$

24,700

53,040
Adjusted

Keithley Current 3

$0.578 \times 10^{-7}$

1.000

1.000

$0.273 \times 10^{-6}$

$0.230 \times 10^{-5}$

1.002

$0.139 \times 10^{-7}$

0.965

$0.297 \times 10^{-7}$

0.986
$1.000 \quad 1.000$

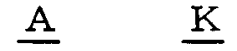

$1.015 \quad 1.045$

$1.000 \quad 1.027$

0.9931 .005

$1.040 \quad 1.045$ 


\section{B. FISSION COUNTER PROGRAM}

Special provisions were made to permit access to the core at one radial position for the purpose of making axial traverses with neutron counters. This was accomplished by removing the safety rod from P03-P00 and replacing it with the TIT, which extended from the operating floor downward 25 feet to just below the reactor core. This access permitted the use of six gas-flow-type absolute fission counters containing microgram quantities of $\mathrm{U}-234, \mathrm{U}-235, \mathrm{U}-236, \mathrm{U}-238, \mathrm{Pu}-239$, and $\mathrm{Pu}-240$. The fission counters were positioned at the bottom of the thimble with the void immediately above the counter filled with an aluminum plug designed to simulate sodium and reduce streaming. Space restrictions allowed only the use of one counter at a time. Axial traverses were accomplished by raising or lowering the TIT. These traverses extended from below the core midplane to more than $100 \mathrm{~cm}$ into the sodium pool, thus extending the axial traverses made with foils in the subassemblies. Moreover, absolute measurements were possible with these chambers, since their efficiencies were nearly unity.

A complete axial traverse required essentially an eight-hour day, so that the fission counter portion of the program required almost 48 hours of reactor time.

The loadings of the fission counters pertinent to this equipment are given in Tables 5 and 6. 
TABLE 5 - URANIUM ABSOLUTE FISSION COUNTER LOADINGS

\begin{tabular}{|c|c|c|c|c|c|}
\hline \multirow[b]{2}{*}{ Principal Isotope } & \multirow{2}{*}{$\begin{array}{c}\text { Mass of } \\
\text { Principal } \\
\text { Isotope, } \mu \mathrm{g}\end{array}$} & \multicolumn{4}{|c|}{ Mass of Component Isotopes, $\mu g^{*}$} \\
\hline & & $\mathrm{U}-234$ & $\mathrm{U}-235$ & $\mathrm{U}-236$ & $\mathrm{U}-238$ \\
\hline$U-234$ & 529 & 529 & $\begin{array}{l}9.98 \\
(11.5) *\end{array}$ & 0.05 & 3.14 \\
\hline$U-235$ & 199 & 2.22 & 199 & 0.61 & 11.66 \\
\hline U-235 & 97 & 1.08 & 97 & 0.30 & 5.73 \\
\hline$U-236$ & 400 & 0.24 & 11.82 & 400 & 2.57 \\
\hline $\begin{array}{c}\text { U-238 } * * \\
\text { (Natural Uranium) }\end{array}$ & 487 & 0.03 & 3.53 & 0 & 487 \\
\hline
\end{tabular}

TABLE 6 - PLUTONIUM ABSOLUTE FISSION COUNTER LOADINGS

\begin{tabular}{|c|c|c|c|}
\hline \multirow{2}{*}{$\begin{array}{l}\text { Principal } \\
\text { Isotope }\end{array}$} & \multirow{2}{*}{$\begin{array}{l}\text { Mass of } \\
\text { Principal } \\
\text { Isotope, } \mu g\end{array}$} & \multicolumn{2}{|c|}{$\begin{array}{l}\text { Mass of Component } \\
\text { Isotopes, } \mu g *\end{array}$} \\
\hline & & Pu-239 & $\mathrm{Pu}-240$ \\
\hline $\mathrm{Pu}-239$ & 133.5 & 133.5 & 0.04 \\
\hline $\mathrm{Pu}-240$ & 504 & $\begin{array}{l}1.72 \\
(3.14)\end{array}$ & 504 \\
\hline
\end{tabular}

* Nominal values are given by the counter supplier (Argonne National Laboratory). The value in parentheses is an independent experimental determination performed by APDA. See Section IV. C. 2.

** Though traverses were made with a depleted uranium counter, discrepancies in its isotopic content prevented meaningful data reduction over much of the traverse. The U-238 counter listed above is one that was used in a preliminary traverse made on September 16, 1963, as part of the absolute power calibration experiment. 
•

• 


\section{ANALYSIS OF RESULTS}

\section{A. FOIL PROGRAM RESULTS}

\section{Data Reduction}

Preliminary irradiations in the TIT permitted adequate pulse height analysis of the gamma spectrum of the various daughter isotopes. Half-life measurements verified that the desired isotope was the predominant gamma emitter. Thus, data reduction was easily accomplished by fitting the appropriate half-life curve to the measured decay by the method of least squares and appropriate corrections for background and reactor power level.

A digital computer code was used to expedite this data reduction except for thorium data, which were reduced by manual calculation. These methods are discussed below.

\section{a. Simple Decay}

A computer program was written to analyze the simple radioactive decay. This program corrected the observed counts from each foil for the natural background and for variations in foil mass. It then calculated the least-mean-square deviation exponential decay curve through the two or three count rate values observed for each foil, using the half-life of the radioactive nucleus obtained from the literature. The resulting curve was evaluated at a given time after the end of the irradiation and the result normalized for reactor power by dividing by the appropriate value for the adjusted integrated count for Channel 3.

\section{b. Fission Product Decay (Thorium)}

The thorium foils were analyzed by correcting for the weight of the foil and then subtracting the background. The natural background in the case of the thorium foils consisted of both the room background and the natural radioactivity of the thorium metal. The combined room and foil background was measured several times during the counting of the thorium foil. After being corrected for mass and background, the foil activity was multiplied by a factor which corrected the time at which the foil was counted to a counting time of eight hours after the end of the irradiations. This factor was obtained from a plot of thorium decay as a function of time normalized to one at eight hours from the end of the irradiation. The resulting value was normalized for power by dividing by the adjusted integrated count 
obtained on Channel 3 of the neutron counting equipment during the time the foil was irradiated.

\section{Experimental Results}

To allow convenient comparis on with the results obtained from calculations, all experimental results were normalized to give unity at the core central plane position at P00-P00. The results of the analys is are given in Table 7 .

The experimental error for the simple decay types, i.e., all but the thorium foils, was estimated by a least-squares treatment of the irradiated foil count rate in combination with a 2.5 per cent $(1 \sigma)$ uncertainty in the reactor power among runs. The resulting 95 per cent confidence limits $(2 \sigma)$ averaged over each subassembly are given in Table 8 . The uncertainty values for thorium were found to be about the same for all subassemblies; however, the uncertainty associated with thorium measurements made at 25.620 inches and 30.630 inches above core midplane were substantially greater than for the other elevations. The 95 per cent confidence limit for these two elevations was estimated to be +11 per cent, while for the other elevations the limit was found to be \pm 7 per cent.

TABLE 8 - THE 95\% CONFIDENCE LIMITS FOR SPECTRUM FOIL RESULTS AS A FUNCTION OF RADIAL LOCATION

$\begin{array}{llllll} & \text { Fe } & \mathrm{Al} & \mathrm{Mn} & \mathrm{Au} & \mathrm{Ni} \\ \text { P00-P00 } & \pm 5.28 & \pm 6.16 & \pm 5.04 & \pm 5.56 & \pm 12.96 \\ \text { P00-P04 } & \pm 5.82 & \pm 6.46 & \pm 5.94 & \pm 5.70 & \pm 12.38 \\ \text { N04-P04 } & \pm 7.48 & \pm 6.60 & \pm 5.16 & \pm 5.54 & \pm 27.78 \\ \text { N04-N04 } & \pm 6.70 & \pm 6.10 & \pm 6.08 & \pm 5.62 & \pm 25.62 \\ \text { N06-P04 } & \pm 5.48 & \pm 6.92 & \pm 11.14 & \pm 5.46 & \pm 9.18 \\ \text { N06-N04 } & \pm 6.08 & \pm 7.28 & \pm 11.92 & \pm 6.08 & \pm 9.08 \\ \text { P00-P10 } & \pm 5.56 & \pm 7.74 & \pm 5.04 & \pm 5.50 & \pm 5.20 \\ \text { P00-P14 } & \pm 6.70 & \pm 6.98 & \pm 5.00 & \pm 13.12 & \pm 70.08 \\ \text { Average } & \pm 6.14 & \pm 6.78 & \pm 6.92 & \pm 6.57 & \pm 21.54\end{array}$


Nominal Foil

\begin{tabular}{|c|c|c|c|c|c|c|c|c|c|}
\hline Material & Elevation, in.* & $\mathrm{P} 00-\mathrm{P} 00$ & P00-P04 & N04-P04 & N04-N04 & N06-P04 & N06-N04 & P00-P10 & P00-P14 \\
\hline \multirow[t]{7}{*}{$\mathrm{Fe}$} & 31.280 & 0.0065 & 0.0031 & 0.0046 & 0.0044 & 0.0028 & 0.0028 & 0.0015 & 0.00027 \\
\hline & 26.270 & 0.0148 & 0.0146 & 0.0110 & 0.0104 & 0.0050 & 0.0087 & 0.0015 & 0.00042 \\
\hline & 22.060 & 0.0443 & 0.0413 & 0.0299 & 0.0288 & 0.0130 & 0.0134 & 0.0024 & 0.00038 \\
\hline & 13.420 & 0.4751 & 0.4784 & 0.3039 & 0.3025 & 0.0534 & 0.0545 & 0.0053 & 0.00055 \\
\hline & 11.220 & 0.6547 & 0.6572 & 0.3991 & 0.4064 & 0.0686 & 0.0689 & 0.0063 & 0.00055 \\
\hline & 6.210 & 0.8742 & 0.8832 & 0.5262 & 0.5357 & 0.0937 & 0.0954 & 0.0079 & 0.00069 \\
\hline & 1.200 & 1.0000 & 0.9954 & 0.5899 & 0.6202 & 0.1051 & 0.1091 & 0.0087 & 0.00071 \\
\hline \multirow[t]{9}{*}{$\mathrm{Al}$} & 32.280 & 0.0085 & 0.0062 & 0.0056 & 0.0053 & 0.0044 & 0.0043 & 0.0031 & 0.00156 \\
\hline & 29.070 & 0.0135 & 0.0093 & 0.0081 & 0.0081 & 0.0054 & 0.0052 & 0.0028 & 0.00143 \\
\hline & 24.060 & 0.0352 & 0.0273 & 0.0179 & 0.0180 & 0.0082 & 0.0088 & 0.0022 & 0.00087 \\
\hline & 20.050 & 0.0823 & 0.0678 & 0.0439 & 0.0429 & 0.0162 & 0.0175 & 0.0026 & 0.00074 \\
\hline & 17.840 & 0.1327 & 0.1036 & 0.0694 & 0.0678 & 0.0230 & 0.0239 & 0.0032 & 0.00073 \\
\hline & 15.630 & 0.2192 & 0.1865 & 0.1185 & 0.1166 & 0.0328 & 0.0328 & 0.0039 & 0.00076 \\
\hline & 9.010 & 0.7398 & 0.6500 & 0.3877 & 0.4057 & 0.0692 & 0.0718 & 0.0061 & 0.00092 \\
\hline & 4.000 & 0.9284 & 0.7966 & 0.4798 & 0.4981 & 0.0851 & 0.0887 & 0.0072 & 0.00103 \\
\hline & -1.010 & 1.0000 & 0.8430 & 0.4999 & 0.5322 & 0.0902 & 0.0945 & 0.0076 & 0.00107 \\
\hline \multirow{8}{*}{ Mn } & 30.730 & 0.5519 & 0.4578 & 0.4186 & 0.4294 & 0.4529 & 0.4700 & 0.3578 & 0.2389 \\
\hline & 25.720 & 0.7952 & 0.5557 & 0.4323 & 0.4649 & 0.3422 & 0.3770 & 0.2242 & 0.1540 \\
\hline & 19.500 & 1.180 & 0.8572 & 0.5983 & 0.6628 & 0.3082 & 0.3705 & 0.1186 & 0.0960 \\
\hline & 17.290 & 1.249 & 0.9451 & 0.6595 & 0.7515 & 0.3322 & 0.4168 & 0.1256 & 0.0888 \\
\hline & 15.080 & 1.089 & 0.8261 & 0.5907 & 0.6893 & 0.3434 & 0.4693 & 0.1387 & 0.0970 \\
\hline & 10.670 & 0.7521 & 0.5745 & 0.4414 & 0.6656 & 0.3687 & 0.7522 & 0.1683 & 0.1086 \\
\hline & 5.660 & 0.8946 & 0.6855 & 0.5190 & 0.8354 & 0.4288 & 0.9473 & 0.1973 & 0.1243 \\
\hline & 0.650 & 1.0000 & 0.7551 & 0.5632 & 0.9073 & 0.4594 & 1.034 & 0.2105 & 0.1302 \\
\hline \multirow[t]{9}{*}{$\mathrm{Au}$} & 29.575 & 0.3089 & 0.2290 & 0.2053 & 0.2162 & 0.2220 & 0.2336 & 0.1751 & 0.1101 \\
\hline & 24.565 & 0.4763 & 0.3366 & 0.2503 & 0.2655 & 0.1582 & 0.1792 & 0.0817 & 0.0521 \\
\hline & 20.555 & 0.6452 & 0.4819 & 0.3428 & 0.3633 & 0.1862 & 0.2143 & 0.0668 & 0.0377 \\
\hline & 18.345 & 0.7580 & 0.5784 & 0.4140 & 0.4512 & 0.2152 & 0.2479 & 0.0736 & 0.0364 \\
\hline & 16.135 & 0.7524 & 0.5806 & 0.4251 & 0.4678 & 0.2362 & 0.2858 & 0.0825 & 0.0374 \\
\hline & 13.925 & 0.6569 & 0.4997 & 0.3725 & 0.4271 & 0.2563 & 0.3446 & 0.0943 & 0.0393 \\
\hline & 9.515 & 0.7366 & 0.5814 & 0.4305 & 0.5561 & 0.3069 & 0.5030 & 0.1167 & 0.0444 \\
\hline & 4.505 & 0.9080 & 0.7012 & 0.5176 & 0.6752 & 0.3611 & 0.6093 & 0.1346 & 0.0490 \\
\hline & -0.505 & 1.0000 & 0.7608 & 0.5483 & 0.7281 & 0.3809 & 0.6428 & 0.1441 & 0.0505 \\
\hline \multirow{9}{*}{$\mathrm{Ni}$} & 30.080 & 0.0082 & 0.0066 & 0.0043 & 0.0043 & 0.0029 & 0.0029 & 0.0009 & 0.00047 \\
\hline & 25.070 & 0.0264 & 0.0179 & 0.0125 & 0.0122 & 0.0059 & 0.0063 & 0.0013 & 0.00044 \\
\hline & 21.060 & 0.0686 & 0.0511 & 0.0337 & 0.0324 & 0.0132 & 0.0143 & 0.0018 & 0.00038 \\
\hline & 18.850 & 0.1174 & 0.0873 & 0.0603 & 0.0577 & 0.0199 & 0.0205 & 0.0023 & 0.00039 \\
\hline & 16.640 & 0.1853 & 0.1497 & 0.0946 & 0.0917 & 0.0280 & 0.0282 & 0.0029 & 0.00041 \\
\hline & 14.430 & 0.3709 & 0.3056 & 0.1985 & 0.1905 & 0.0395 & 0.0404 & 0.0036 & 0.00044 \\
\hline & 10.020 & 0.6821 & 0.5949 & 0.3571 & 0.3688 & 0.0654 & 0.0660 & 0.0049 & 0.00052 \\
\hline & 5.010 & 0.9025 & 0.7611 & 0.4543 & 0.4744 & 0.0839 & 0.0839 & 0.0062 & 0.00056 \\
\hline & 0.000 & 1.0000 & 0.8356 & 0.4915 & 0.5156 & 0.0908 & 0.0934 & 0.0066 & 0.00062 \\
\hline \multirow[t]{8}{*}{$\mathrm{Th}$} & 30.630 & 0.0067 & 0.0056 & 0.0039 & 0.0044 & 0.0024 & 0.0022 & 0.0009 & 0.00025 \\
\hline & 25.260 & 0.025 & 0.017 & 0.012 & 0.012 & 0.0053 & 0.0051 & 0.0012 & 0.00030 \\
\hline & 19.400 & 0.117 & 0.090 & 0.061 & 0.056 & 0.018 & 0.020 & 0.0023 & 0.00033 \\
\hline & 17.190 & 0.183 & 0.145 & 0.096 & 0.091 & 0.026 & 0.028 & 0.0027 & 0.00035 \\
\hline & 14.980 & 0.309 & 0.250 & 0.166 & 0.158 & 0.037 & 0.038 & 0.0038 & 0.00037 \\
\hline & 10.570 & 0.664 & 0.566 & 0.347 & 0.352 & 0.063 & 0.063 & 0.0048 & 0.00046 \\
\hline & 5.560 & 0.891 & 0.746 & 0.454 & 0.462 & 0.081 & 0.084 & 0.0061 & 0.00053 \\
\hline & 0.550 & 1.000 & 0.829 & 0.497 & 0.516 & 0.091 & 0.092 & 0.0068 & 0.00056 \\
\hline
\end{tabular}

\footnotetext{
* Above and below core midplane.
} 


\section{Comparison with Calculation}

The resulting measured axial distributions in each subassembly are shown graphically in Figures 22 and 23. Evaluated distributions were obtained using two multigroup diffusion models with the CRAM code. Nine neutron energy groups clustered mainly in the 0.3 to $10 \mathrm{Mev}$ region were used for the threshold reactions. A 20-group model was used for the nonthreshold reactions. The most significant result of the threshold detector axial distributions is that the slope outside the core agrees quite well with calculations and is essentially the same for all isotopes. The larger discrepancies near the top of the subassemblies are due to an increase in the worth of competing $(n, \gamma)$ reactions and to the poor counting statistics. It was not possible to operate the reactor at sufficient powers to produce high counting rates on these foils, since the dose rate near the glove box due to subassembly activation would have become excessive. However, some of the discrepancy may be real, since it can also be seen in the midplane radial distribution shown in Figure 24, where counting statistics remain good for all radial positions. The implied increase in fast flux in subassembly P00-P14 may reflect the discrepancies that had been noted earlier in the U-235 distributions, i.e., the U-235 fission rate does not fall off as sharply as calculations indicate and this effect is accentuated if there is not good energy definition in the lower neutron energy groups. ${ }^{5}$ However, both radially and axially, there appears to be little change in the relative reaction rates among different isotopes as a function of position. This would indicate that there are no strong positiondependent changes in the spectrum at energies greater than about $1 \mathrm{Mev}$.

Gold and manganese ir radiations show marked effects due to spectral softening. The axial distributions (see Figure 20) reflect the same sharp increases in rates in and near the end gaps as observed with U-235 foils. The overprediction of these increases is due to the use of infinite dilute capture cross sections in the low energy resonance regions for both manganese and gold, 6 where most of the capture takes place for points near the top of the subassemblies.

Comparison of the gold and manganese responses in lattice position N04-N04 with those in position N04-P04 indicates the effect of spectral softening that arises from the antimony-beryllium neutron source in position N05-N04 (see Table 7). The Sb-Be source subassembly is $55 \mathrm{v} / 0$ beryllium. 


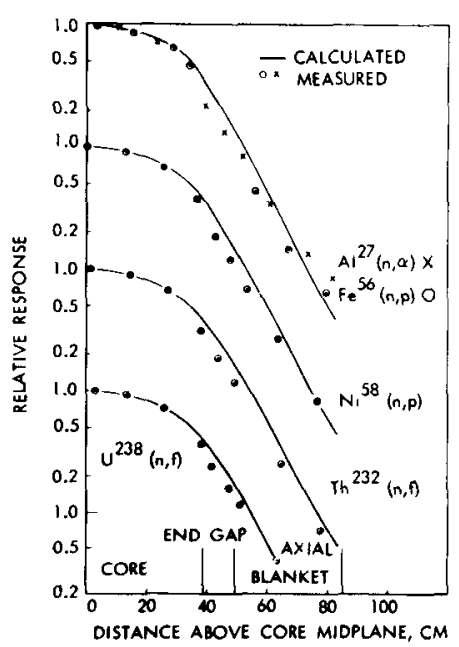

POO-POO

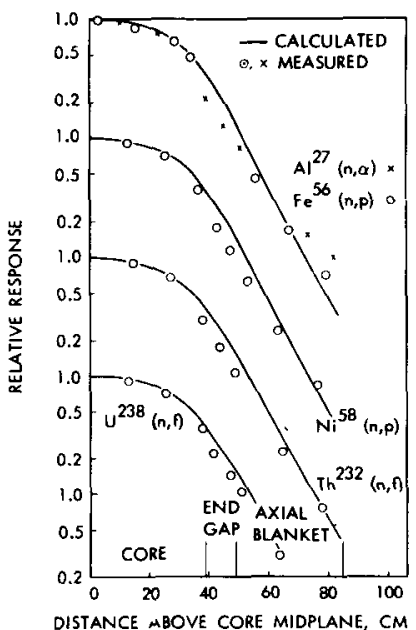

NO4-NO4

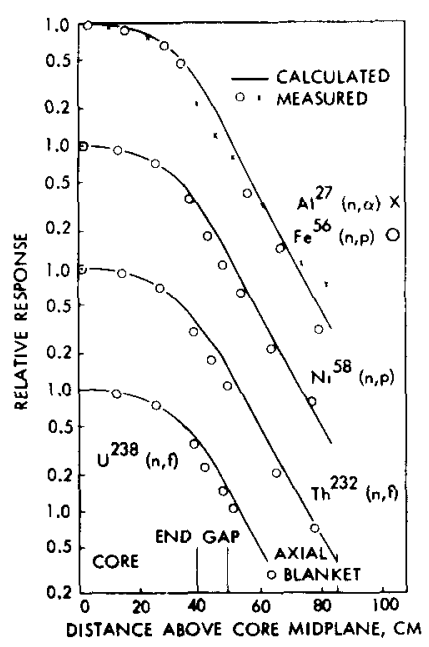

$\mathrm{POO}-\mathrm{PO4}$

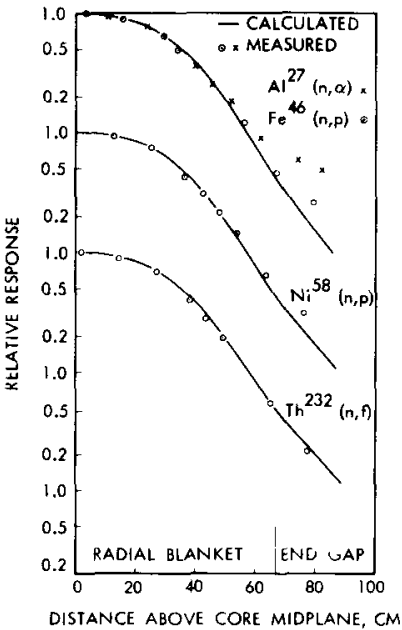

N06-PO4

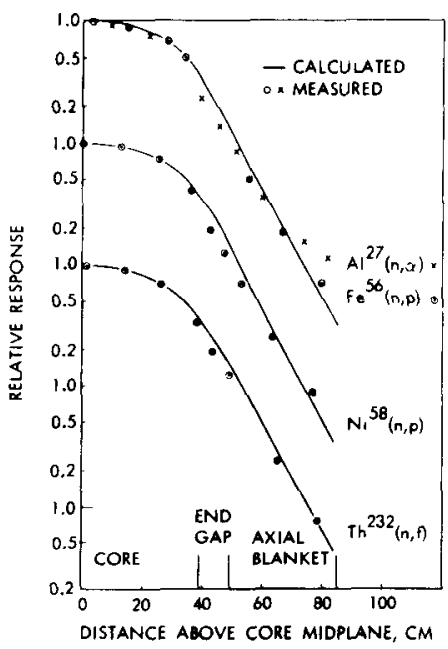

NO4-PO4

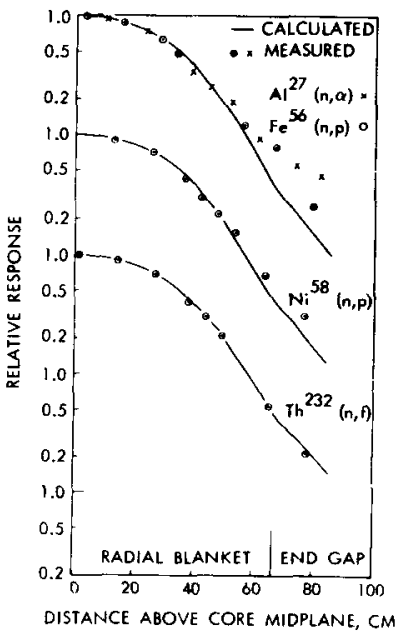

No6-NO4

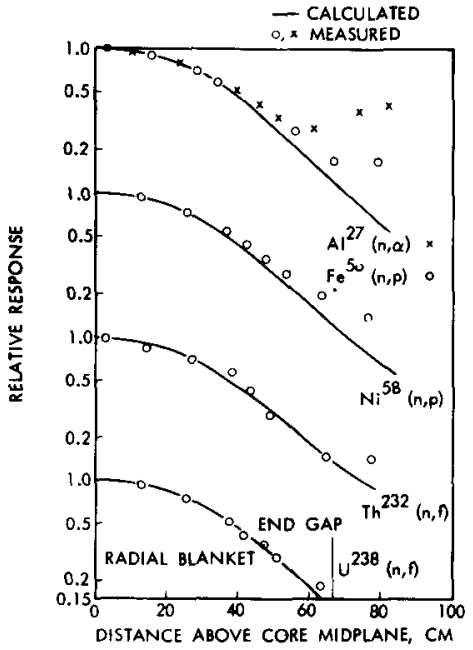

POO-P10

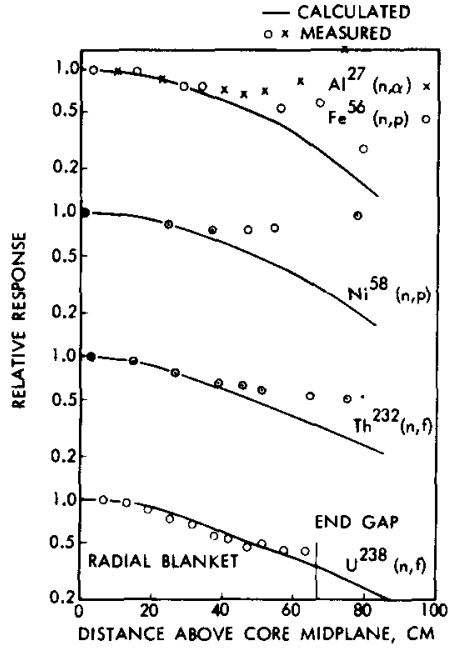

POO-PI 4 AT DIFFERENT LATTICE POSITIONS 

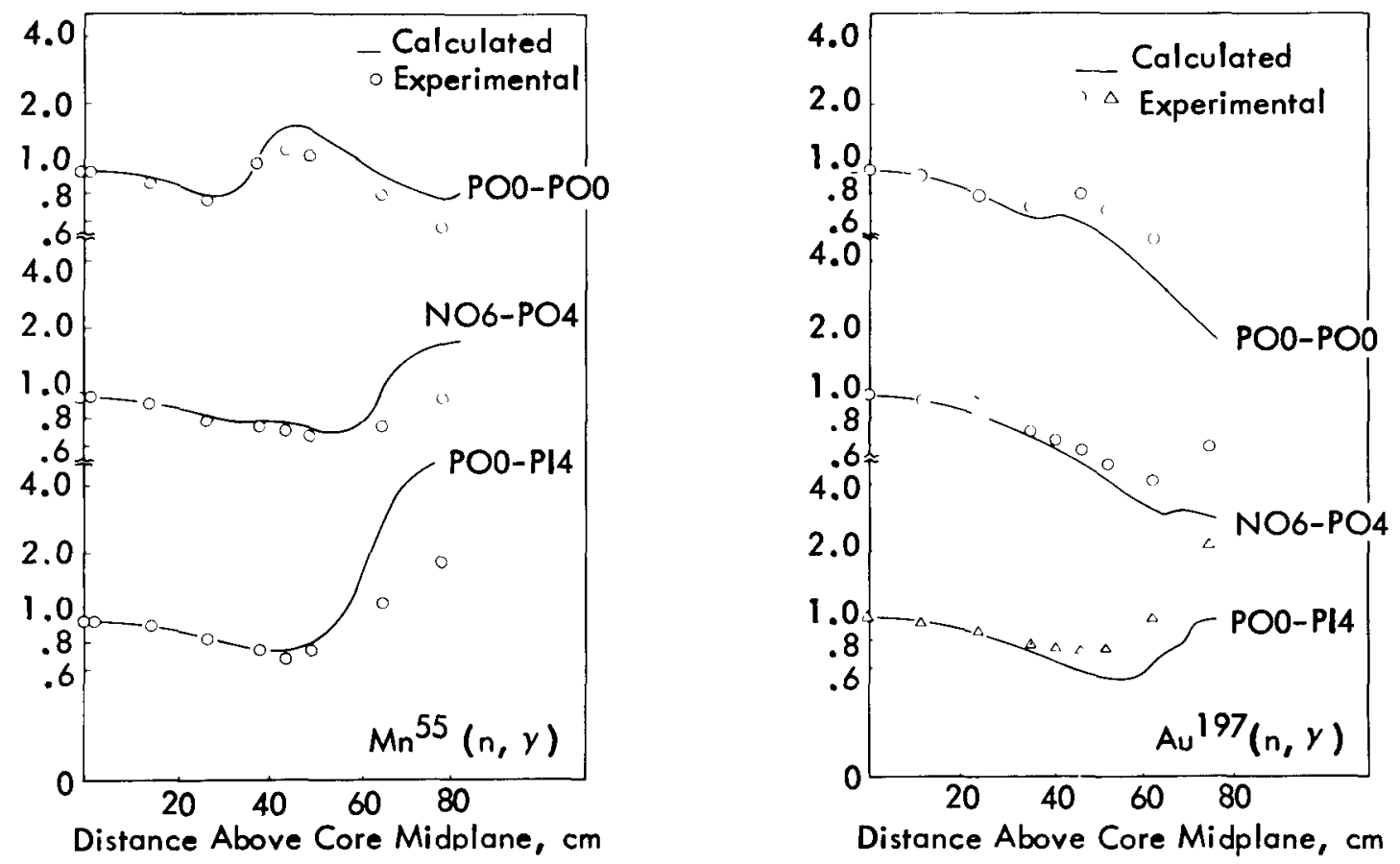

FIG. 23 AXIAL RESPONSE DISTRIBUTIONS

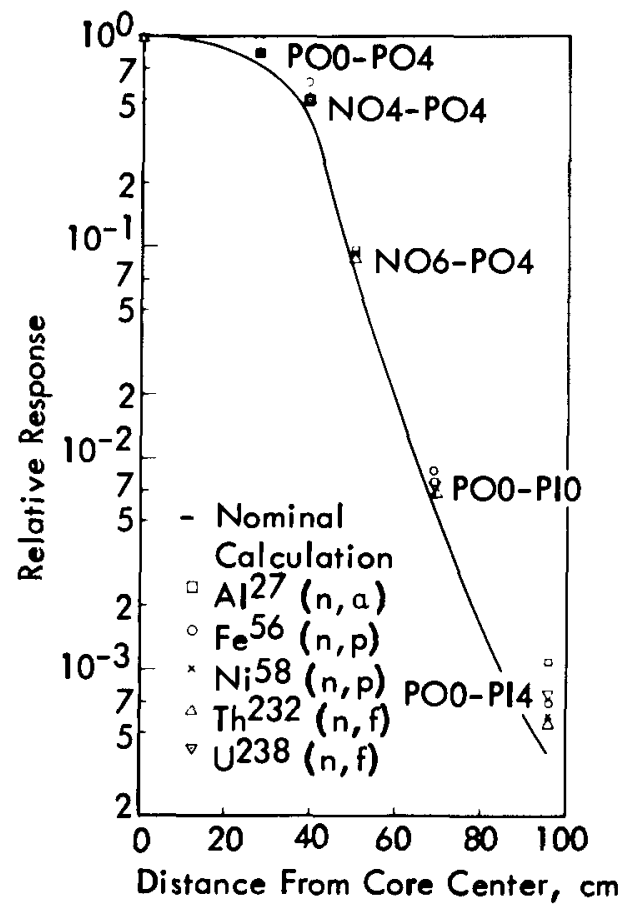


Increases near the core midplane of $33 \%$ and $61 \%$ are observed for gold and manganese responses, respectively, while the increase in the U-235 fission rate had been measured to be $8 \%$. These values as predicted by an eightgroup, two-dimensional CRAM ${ }^{4}$ calculation in XY geometry were $27 \%, 67 \%$, and $12 \%$, respectively. The gold and manganese response increases are expected to be greater because their capture cross sections increase monotonically with decreasing neutron energy, while the U-235 fission cross section exhibits a minimum in the energy range of interest. The increases in capture responses in the blanket position N04-N04 compared with N06-P04 were measured to be $69 \%$ and $125 \%$ for gold and manganese, respectively; corresponding data were not available for U-235. The effect of the neutron source on threshold activations can be observed, but is only of the order of a few percent.

\section{B. FISSION COUNTER PROGRAM RESULTS}

\section{Axial Traverses}

The axial traverses made in the TIT with threshold-type fission counters exhibited the same general trend as the threshold foils. However, the lower threshold reactions exhibited correspondingly slower decreases in response with increasing distance from the core. Thus, the slope of the $U-234$ fission distribution is the smallest, while that for $U-238$ is very similar to the nonfissionable threshold detectors in the core. Use of the TIT and the relatively large cross sections for fissionable threshold reactions allowed traverses to greater elevations than with the foils. Meaningful traverses were made to elevations as great as $140 \mathrm{~cm}$ from the core midplane, as compared to elevations of 60 to $80 \mathrm{~cm}$ for the nonfissionable foils. Distributions for U-234 and U-236 may be found in Figures 25 and 26, respectively, and the distribution obtained with natural uranium is given in Figure 27. Comparison with calculations resulted in the same general trend as for the foils; that is, excellent reproduction of the asymptotic slope in the axial blanket and minor disagreement in the vicinity of the end gap.

The information of greatest interest obtained from the fission counter traverses is the axial distributions for $\mathrm{U}-235$ and $\mathrm{Pu}-239$ (since they extend quite far into the sodium pool) and the in-core fission ratios (since these are the only absolute form of spectral indices that were measured). Measured axial distributions for U-235 fission and Pu-239 fission are given in Figures 28 and 29. (Absolute normalization relative to reactor power is based on the results of a 2-dimensional, 8-group calculation of a 99.5 subassembly core in RZ geometry.) Fission ratios are given in Table 9. It should be noted that the U-238/U-235 fission ratio is based on measurements made as part of the absolute power calibration program and utilized a natural uranium counter and both the $97 \mu \mathrm{g}$ and $199 \mu \mathrm{g}$ U-235 counters. The loading of the highly depleted U-238 counter nominally used in the fission counter traverses was found to be too inaccurate to allow 


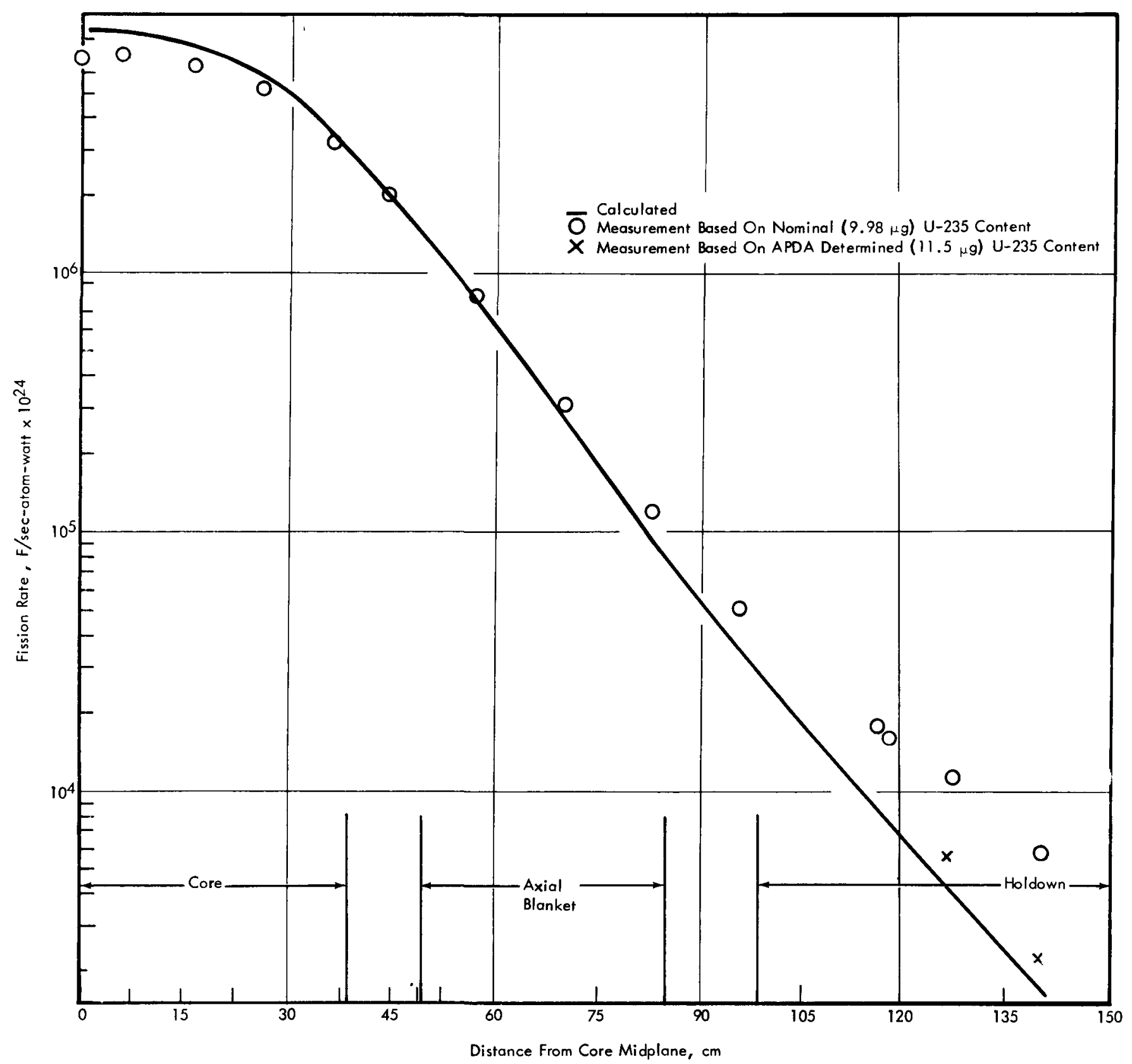

012868

FIG. 25 U-234 AXIAL FISSION DISTRIBUTION IN EMPTY SAFETY ROD CHANNEL OF THE EFFBR 


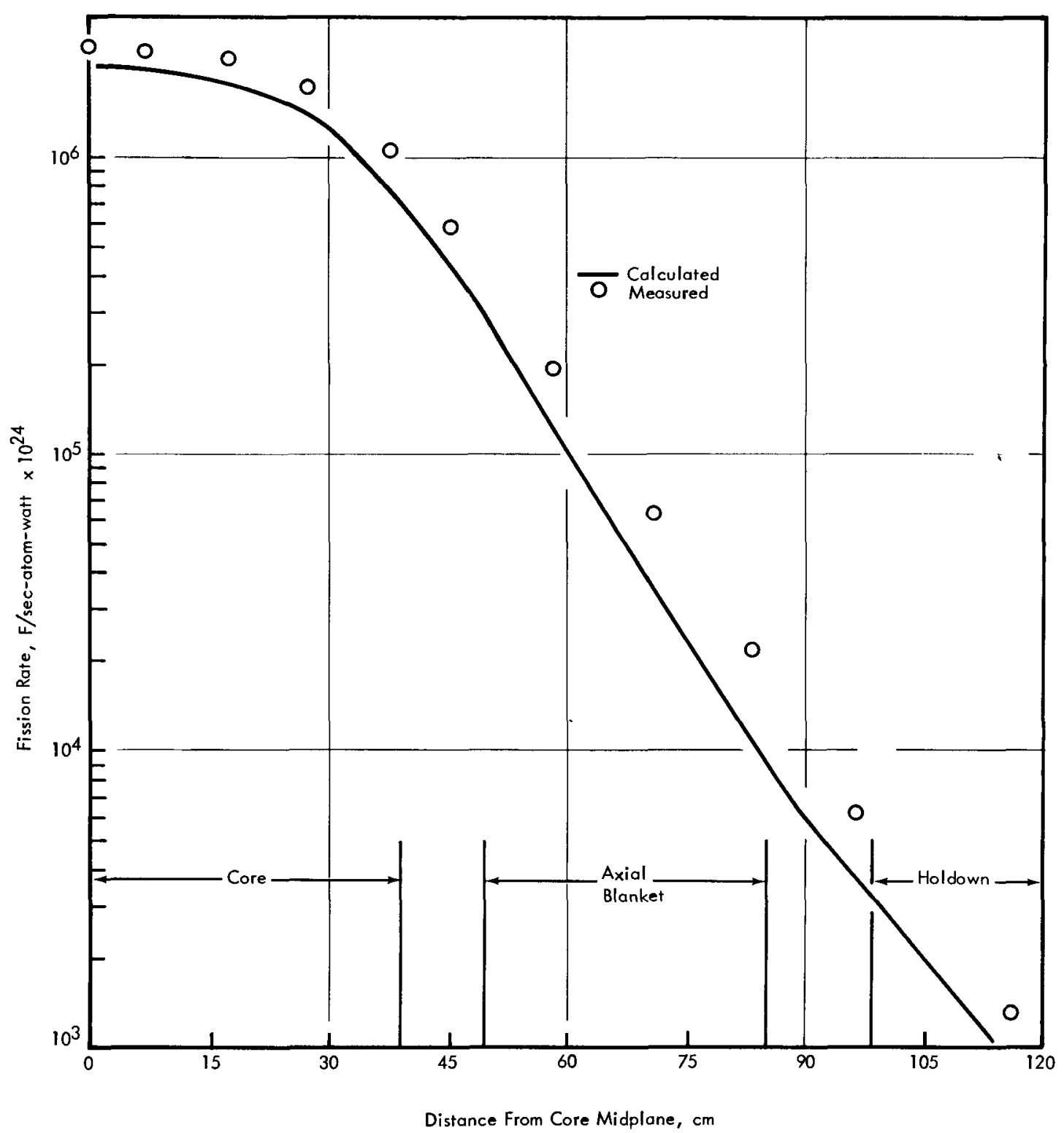




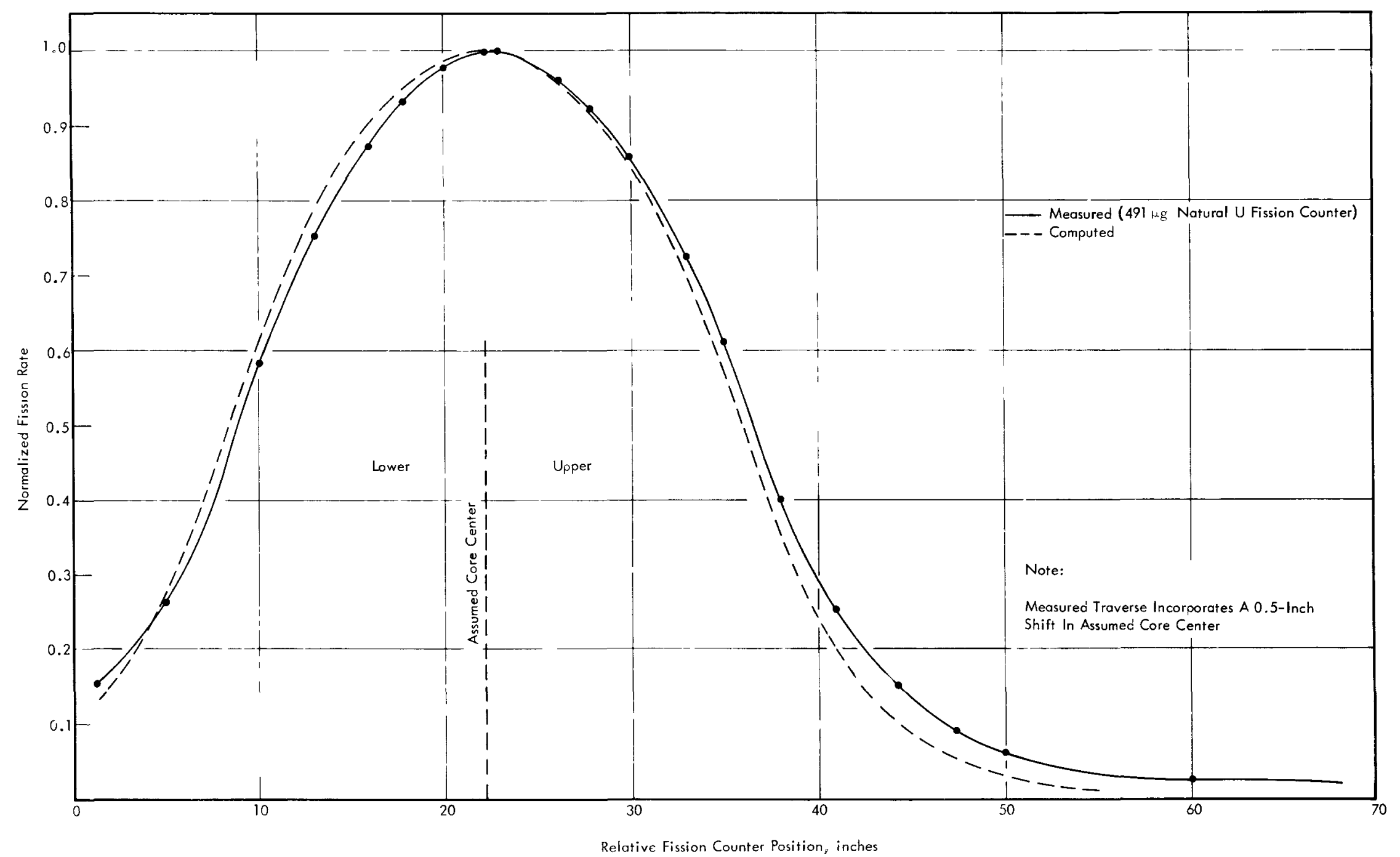

013068

FIG. 27 AXIAL FISSION DISTRIBUTION FOR NATURAL URANIUM IN CORE A 


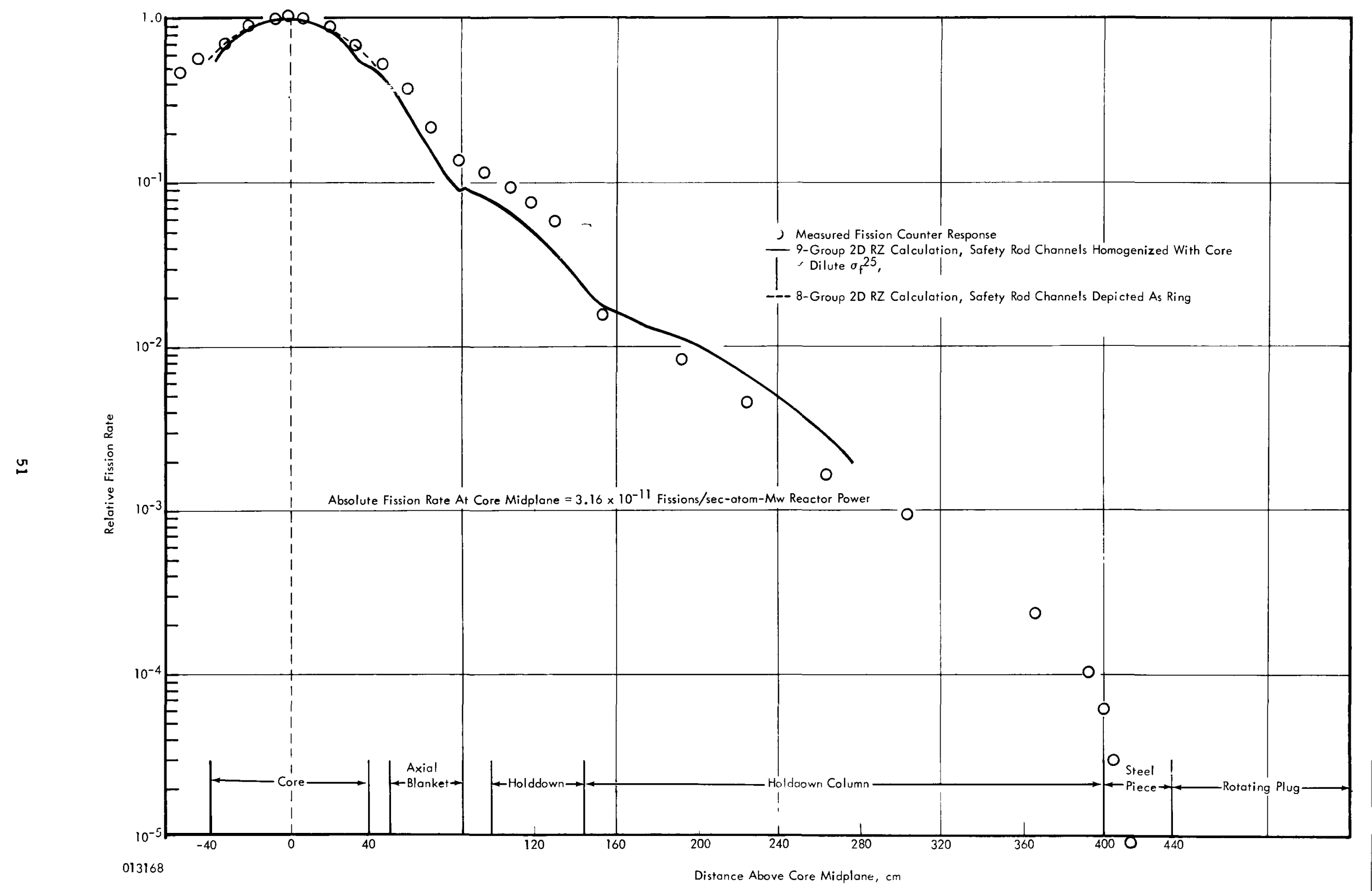

FIG. 28 U-235 AXIAL FISSION DISTRIBUTION IN THE TEMPORARY INSTRUMENT THIMBLE (P03-POO) 


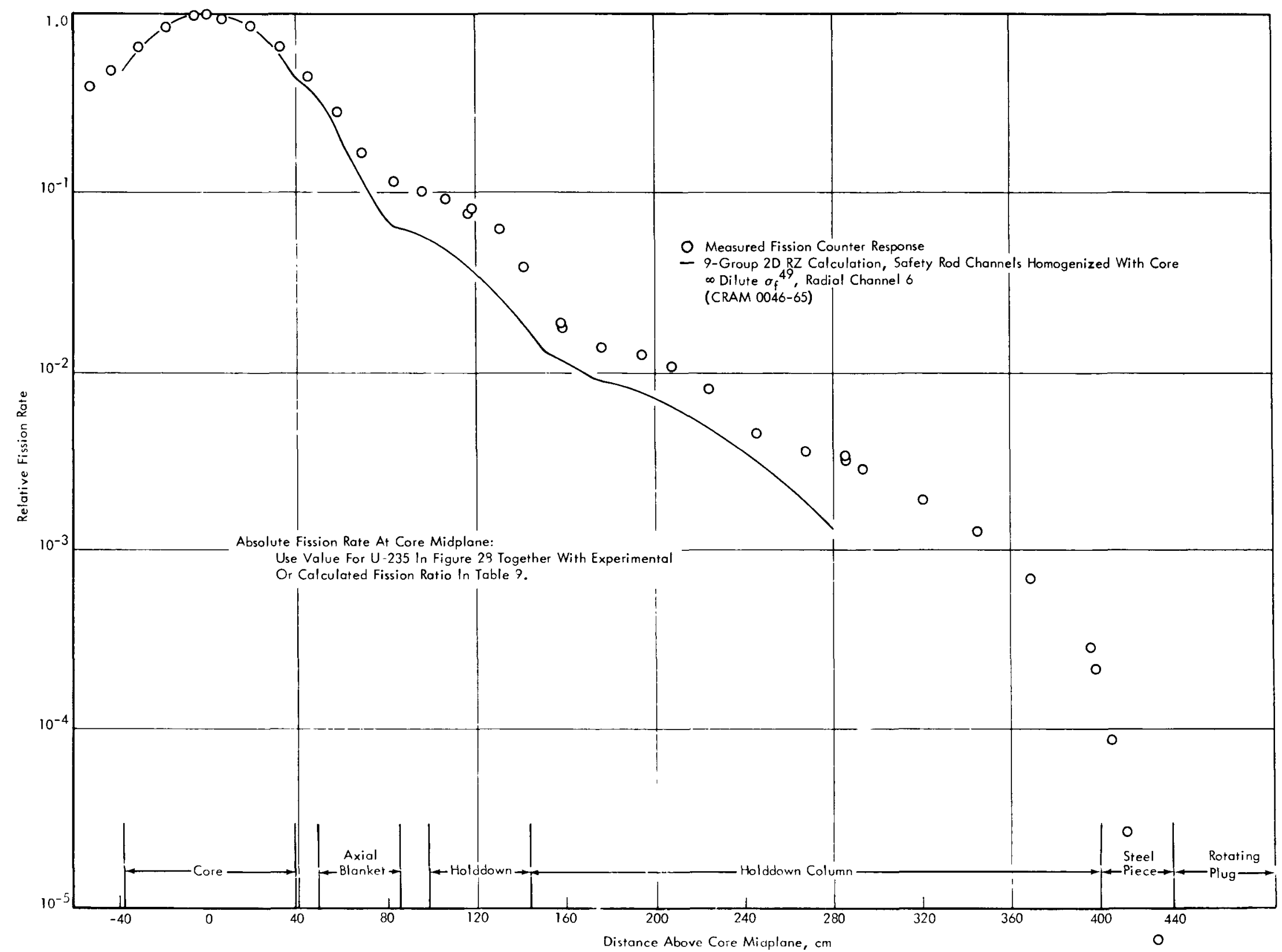

FIG. 29 PU-239 AXIAL FISSION DISTRIBUTION IN THE TEMPORARY INSTRUMENT THIMBLE (P03-POO) 
TABLE 9 - FISSION RATIOS IN THE TEMPORARY INSTRUMENT THIMBLE AT CORE MIDPLANE

Calculated

$\begin{array}{ll}\text { Measured } & \text { Nominal 2D } \\ \text { Multigroup }\end{array}$
26.8
12.5
$3.75^{* * * * *}$

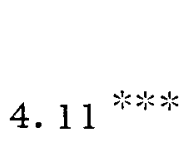
$\mathrm{f}_{25} / \mathrm{f}_{28}$
$\mathrm{f}_{25} / \mathrm{f}_{26}$
$\mathrm{f}_{25 / \mathrm{f}_{40}}$
$\mathrm{f}_{25} / \mathrm{f}_{24}$
$f_{25} \mid f_{49}$
25.3
$\mathrm{f}_{25} / \mathrm{f}_{28}$
$\mathrm{f}_{25} / \mathrm{f}_{26}$
$\mathrm{f}_{25 / \mathrm{f}_{40}}$
$\mathrm{f}_{25} / \mathrm{f}_{24}$
$\mathrm{f}_{25} / \mathrm{f}_{28}$
$\mathrm{f}_{25} / \mathrm{f}_{26}$
$\mathrm{f}_{25 / f_{40}}$
$\mathrm{f}_{25 / f_{24}}$
0.931
10.3
3.3
3. 3

(2) 9

25.3

11.0

3.0

3.3

New BNL-325 and

Continuous Spectrum **

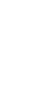

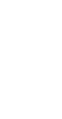


extensive use of the resulting data. Corrections for structural scattering are included in the ratios involving threshold fission isotopes (see Section IV. C. 3).

Since the reaction rate measurements at points relatively distant from the core are of particular interest, a comparison is made between measurements and calculation for the axial U-235 and Pu-239 fission distributions in the TIT (see Figures 27 and 28). Fluxes for the calculated distributions are from a 9-group 2-dimensional CRAM problem using the 6APDA library. Reaction rate fission cross sections for U-235 and Pu-239 are the infinite dilute option of the 7-APDA library. ${ }^{2}, 8$ The major sources of difference between calculation and experiment are (1) limitations of diffusion theory at great distances from the source, (2) inadequate makeup of the complex structure above the core, (3) use of core flux weighting to form elastic removal group core sections in scattering media far from the core, and (4) inadequate representation of the resonance cross sections in multigroup format in the 6-APDA and 7-APDA libraries.

\section{Neutron Spectrum Determination}

Since the use of absolute fission counters afforded the only absolute measure of reaction rates, any direct spectrum determination relied on those measurements. The four threshold fission counter measurements at the core midplane were used to construct a high-energy spectrum using the straightforward effective threshold technique. ${ }^{9}$ Cross sections for U-234 and U-236 were taken from Hughes and Swartz 10 and for U-255, U-238, and $\mathrm{Pu}-240$ from Stehn et al.11 An assumed spectrum constructed from 24-group diffusion theory calculations is shown in Figure 28. An effective threshold is determined that gives the same calculated reaction rate with an assumed rectangular-shaped cross section as with the true cross section. The measured reaction rates can then be used to determine relative flux magnitudes over energy ranges defined by these effective thresholds. The appropriate thresholds are given together with pertinent fission ratios in Table 10. Uncertainties in the measured values are estimated to be $7 \%$.

The resulting spectrum is shown in histogram form normalized to agree with $\mathrm{U}-238$ fission rate above $1.5 \mathrm{Mev}$ (Figure 28). Since there were inconsistencies in the calibration that led to the stated total plutonium loading of the $\mathrm{Pu}-240$ counter, the spectrum is also shown as determined with only three of the isotopes, $\mathrm{Pu}-240$ being omitted. The results indicate that the spectrum for energies greater than $0.5 \mathrm{Mev}$ is harder than calculated. This is borne out by a comparison of measured and calculated fission ratios shown in Table 10 . 
Effective Threshold

\section{Lethargy}

$\mathrm{U}-234$

$\mathrm{Pu}-240$

$\mathrm{U}-236$

$\mathrm{U}-238$
3. 0

2. 8

2.3

1.9
Energy

0.5

0.61

1.0

1.5
Fission Rate per Atom Relative to U-238

$\underline{\text { Calculated }}$

Measured

7.73

6.52

8.47

7. 12

2. 30

2. 14

However, it should also be pointed out that the measured U-235 to U-238 fission ratio (measured by counters and by radiochemical analysis of foils) is greater than the calculated value by about $6 \%$. This suggests that the real spectrum below about $0.5 \mathrm{Mev}$ is softer than calculated, leading to a combined effect of a low - and a high-energy tail greater in magnitude than predicted.

Although only four threshold measurements were available, an attempt was made to reconstruct the spectrum by applying a least-squares analysis to the data in the lethargy interval $u=0$ to 6 . The method is similar in principle to that given by DiCola and Rota, 12 but it seemed more appropriate to use lethargy as the independent variable. The spectrum obtained from multigroup calculations (Figure 29) was used as the lowestorder approximation and the expansion was carried out to the second order. A flat correction was assumed from $u=3$ to 6 with a connected parabola in the interval $u=0$ to 3 , since the reaction rate from the lower energy region is so much less significant. The resulting parabolic correction factor (correct flux/flux guess) is very nearly a straight line with a slope that tends to increase the flux with increasing energy. The magnitude of the correction is about $10 \%$ greater than that implied by the histogram spectrum shown in Figure 30. The approach suffers somewhat from lack of data, since the least-squares technique is applied to essentially only three data points for a system requiring two points to determine the coefficients. However, the trend of a higher flux at higher energies is felt to be correct.

\section{SOURCES OF EXPERIMENTAL ERROR}

A discussion of the sources of experimental error is important, inasmuch as it points out some of the basic difficulties inherent in these types of measurements in general and in this reactor environment in particular. Only those sources of error that were felt to be relatively large or unique to this program are discussed here. 


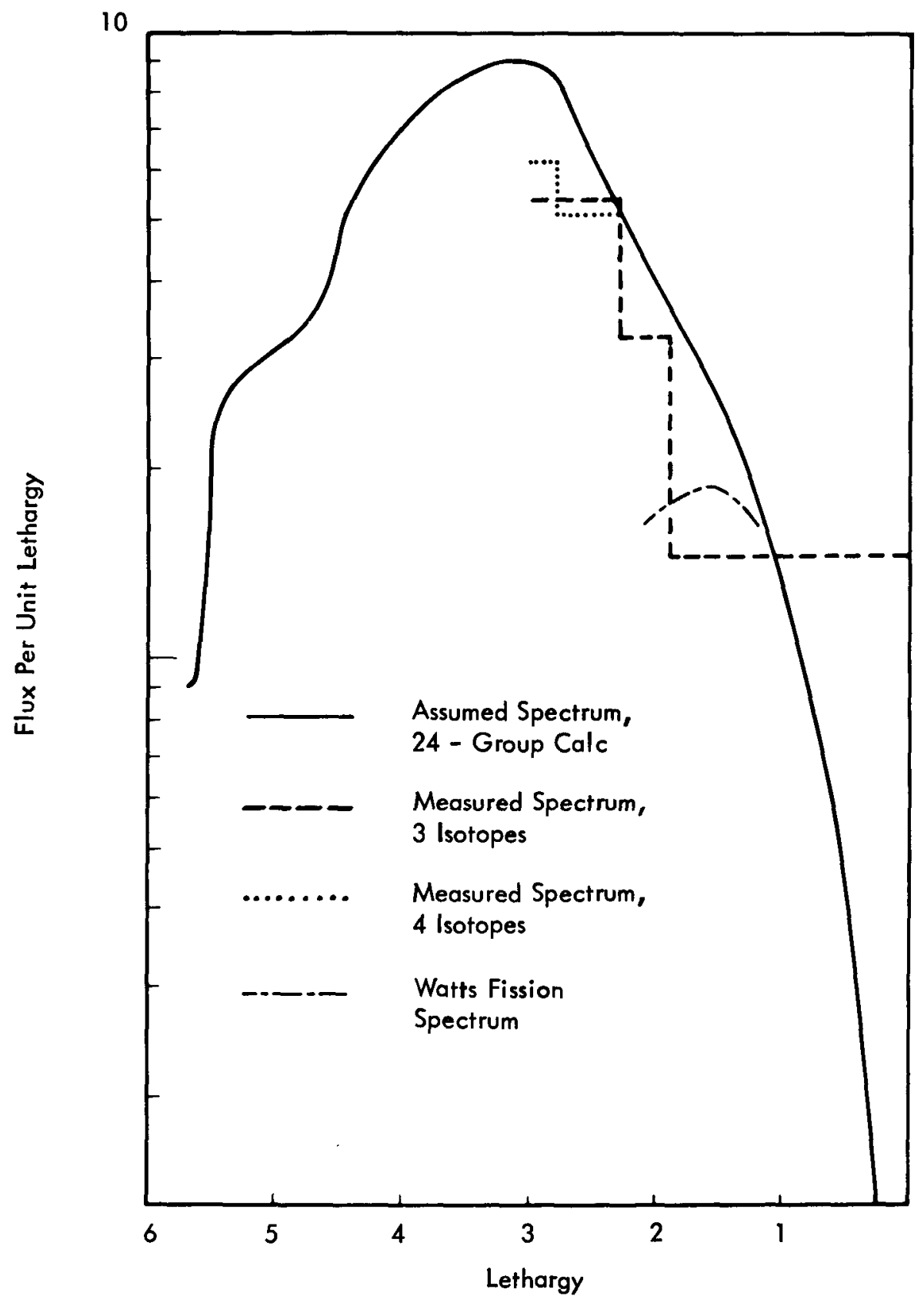




\section{Power Normalization}

Both the foil and fission counter measurements relied on external neutron detectors to normalize the reactor power between differeni runs. This technique was required in the case of the counters because it was physically impossible to use more than one counter at a time in the TIT. It was required in the case of the foils because the TIT had been replaced by an oscillator rod before the threshold foil irradiations. Thus there was no convenient location to irradiate normalization foils with each subassembly irradiation. Every attempt was made in the case of the foil irradiations to repeat the trapezoidal power shape as closely as possible with each run. The major source of error was felt to arise from inconsistencies in the various external detector readings among different runs due to electronic drift or possible temperature effects. These inconsistencies are estimated to result in an uncertainty of $\pm 3 \%$ for both foils and counters when comparing results from one run with those of another. Thus, the fission ratio measurements are affected, as are the radial foil distribution measurements.

\section{Fission Counter Masses}

Preliminary traverses made with some of the fission counters revealed some inaccuracies in the stated masses of impurity fissile isotopes in some of the threshold fission counters. As a result, some of the counters were recalibrated off-site, revealing some errors in the total loading as well. It was felt that consistent loading data were obtained for the U-234, U-236, Pu-239 and U-235 counters. Some uncertainty exists for the Pu-240 counter, while the depleted U-238 counter data were excluded. The U-238 counter measurements that have been reported were obtained with a natural uranium counter and are felt to be quite accurate at the core midplane.

While there was no on-site technique for establishing the total mass loadings of threshold fission counters, a simple technique was evolved for establishing the mass of the major fissile impurity, U-235 or Pu-239. Traverses were made far up into the sodium pool with both the threshold and corresponding fissile counter. The assumption is made that the spectrum is sufficiently soft for all fissions from the threshold counter of interest to be due to the fissile impurity, thus leading to a value for the mass of the fissile impurity. If the assumption is not correct, the resulting mass will be position dependent; however, if an asymptotic value is achieved, the assumption may be taken as valid and the fissile impurity mass is obtained. The values obtained in this manner, when different from the stated values, led to better agreement between measured and calculated fission distributions. See Figure 25. 


\section{Stainless Steel Scattering}

It has been shown that inelastic scattering in stainless steel surrounding threshold-type materiafs significantly affects the threshold reaction rates. 12 Though the foils were inside a stainless steel tube which was inserted into a stainless steel sheath, it was not felt that the scattering effect would disturb the resulting relative spatial distributions. However, the absolute measurements made with threshold-type fission counters are seriously affected by such scattering. A correction factor to multiply the observed fission rate to obtain the true fission rate was obtained in the following manner. A mean chord length for neutron travel into the counter from the active core was estimated for the current counting geometry. This length was also estimated for the counting geometry in the zero power reactor ZPR-III (Figure 31) where correction factors have been reported.13

Correction factors were then obtained by extrapolating the values of Davey in accordance with the two different mean chord lengths, assuming an exponential form of neutron attenuation.

\section{Fission Rate \\ Correction Factor}

$$
\begin{array}{r}
U-234 \\
P u-240 \\
U-236 \\
U-238
\end{array}
$$

$1.05 \pm 0.02$

$1.05 \pm 0.02$

$1.08 \pm 0.03$

$1.10 \mp 0.04$

It is interesting to note that in all cases an increase in this correction factor would improve agreement with calculated fission ratios.

\section{Counting Statistics, Background, and Impurity Isotopes}

The effects of counting statistics, background, and impurity isotopes, previously mentioned briefly, were found to be a limiting factor only for nonfissionable threshold foils near the subassembly handling heads. It was somewhat surprising, however, that aluminum behaved as poorly as it did in that area, since the half-life of the daughter isotope was quite clearly observed, and one standard deviation was only $\pm 8 \%$ with the effect of background included. 


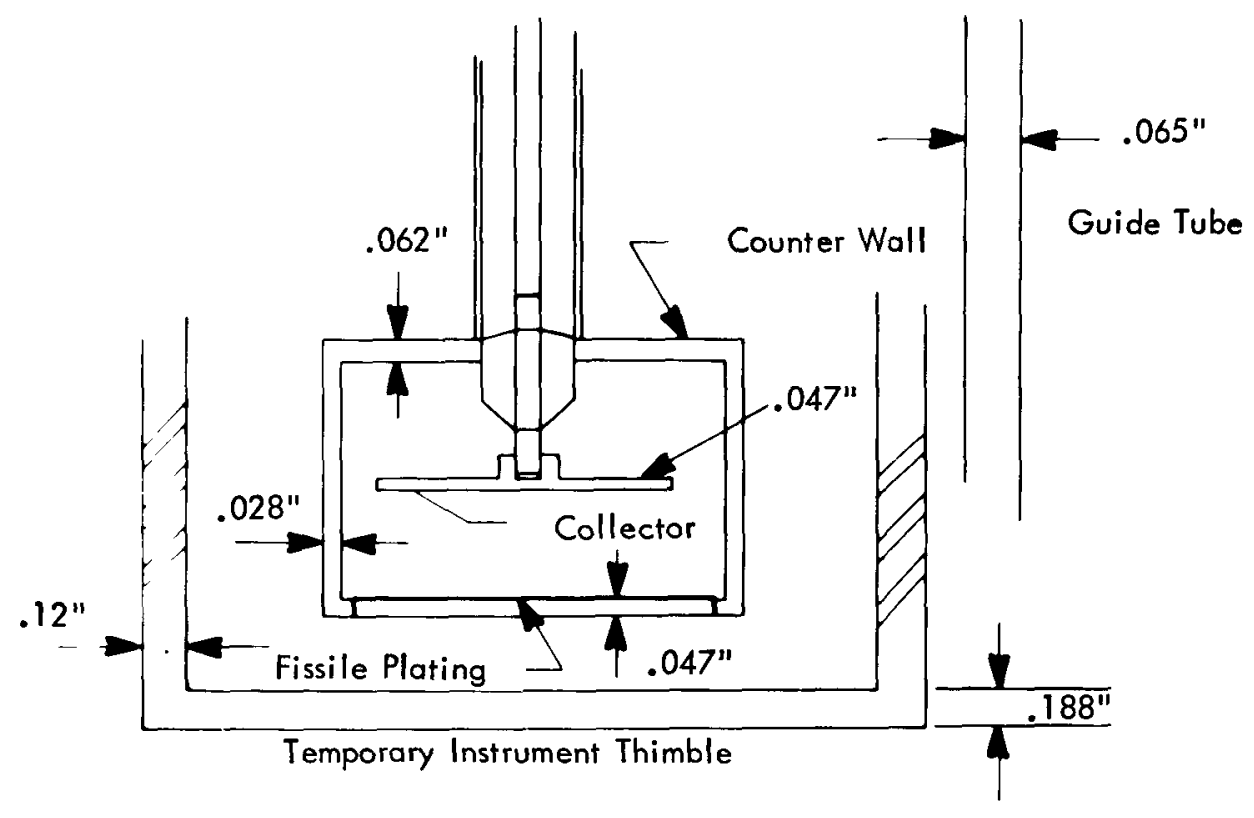

(A) EFBR COUNTER GEOMETRY

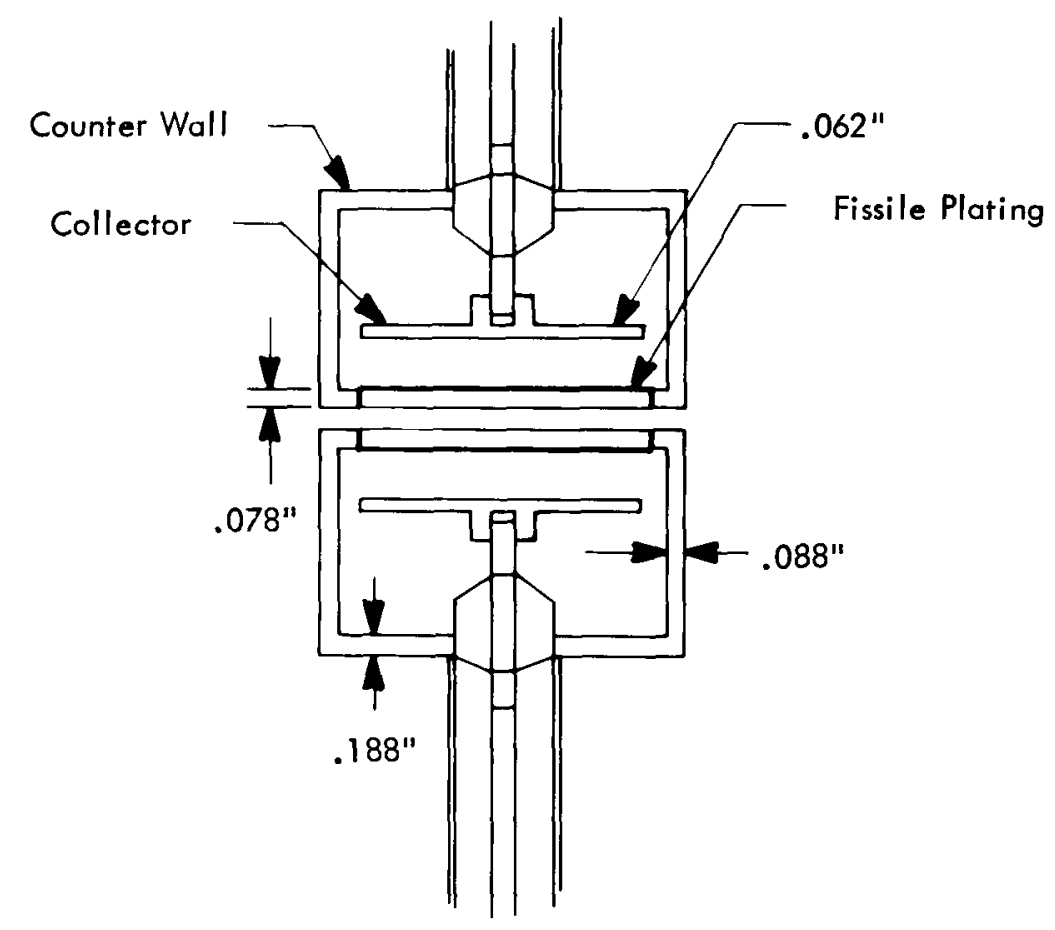

(B) ARGONNE KIRN COUNTER GEOMETRY 
-

- 


\section{CONCLUSIONS}

The general good agreement of measured distributions with those obtained by standard multigroup techniques lends confidence in the latter techniques for predicting flux levels and reaction rates at some distance from the core, as well as in the core proper. This agreement applied to the high energy fluxes at large axial distances from the core midplane is of some importance, since radiation damage estimates due to atomic displacements for the more critical reactor components such as the support plate, subassembly spring, and holddown fingers are quite sensitive to the magnitude of these fluxes. Verification of the absolute flux level in the core above $1 \mathrm{Mev}$, as implied by the U-238 to U-235 fission ratio agreement, together with high energy response distribution data supplied by the foils near the edge of the core, will be of particular interest to experimenters who tentatively plan to use core edge and the first row of blanket lattice positions for the irradiation of structural materials. The flux above $1 \mathrm{Mev}$ at these positions should be predictable to within about $10 \%$ for a given reactor power, since the reactor power as determined from heat balance measurements on the steam side agrees with a nuclear determination based on the in-core U-235 fission counter response to within about $2 \%$.

The low energy flux perturbation observed near the neutron source must be taken into account when predicting burnup for both core and blanket subassemblies adjacent to the neutron source position. Neglect of this phenomenon could lead to excessive burnup and overheating.

The rather sharp increases in low energy reaction rates near the outer edges of the blanket given directly by the gold and manganese foils, implied by the threshold foils, and supported by earlier U-235 foil measurements ${ }^{3}$ are of particular concern as they relate to blanket heating. Early heating predictions based on few-group fluxes underestimated these increases, and as a result current temperature measurements are higher than the earlier predictions. These discrepancies would tend to increase with burnup, since plutonium build-up is due mainly to low energy fluxes. Thus, blanket heating predictions at full burnup have been re-evaluated.

Cross section uncertainties as they relate to the spectrum determination technique described here using fission counters remain a major problem. No attempt is made to attach uncertainty values to these fission cross sections; however, the definite and consistent trend of the threshold fission ratios relative to $U-235$ (all measured values are lower than calculated) lend credence to the qualitative conclusion that the high energy neutron spectrum tail is greater than predicted. 
In general, one can say that a limited foil and counter program comparable to that outlined here can be carried out in a sodium-cooled fast power reactor with success despite the problems of limited access and environment. However, strong emphasis should be placed on techniques for maintaining accurate power normalization and ascertaining accurate fission counter loading data if meaningful absolute spectrum measurements are to be made. An on-site system for making absolute alpha counts of the fissile plates would be very useful in this regard.

Such a program would probably not offer any significant improvement over multigroup techniques for spectrum determination for points within the core until cross section uncertainties can be reduced to less than about $5 \%$. Further, alternate techniques suitable only in critical experiments will probably surpass the foil technique in accuracy and detail for an absolute measurement of neutron spectra. However, use of the core spectrum as a standard allows these simple foil and counter techniques to infer spectrum information and reaction rate distributions exterior to the core that represent definite improvements over multigroup diffusion theory. 


\section{REFER ENCES}

1. Power Reactor Development Co., "Technical Information and Hazards Summary Report, Enrico Fermi Atomic Power Plant," Vol. 1-9, Revised to March 1964.

2. Page, E. M., et al, "Measurement and Calculation of the U-235 and U-238 Fission Distribution and U-238 Capture Distribution for the Enrico Fermi Fast Breeder Reactor, "APDA-NTS-10, 1967.

3. Goldman, D. T。, Chart of Nuclides, Knolls Atomic Power Laboratory, Seventh Edition, Revised to June 1964.

4. Hassit, A., "A Computer Program to Solve the Multigroup Diffusion Equation, "TRG Report 229 (R), 1962.

5. Horne, R. E., and Page, E. M., "Measured and Calculated Fission Distribution in the Enrico Fermi Reactor," ANS Trans. 7, No. 2, pp 494-495, 1964.

6. Keeney, W. P., ANS Trans. 9, pp 187-189, 1966.

7. Edwards, J. J., et al, "Fast Reactor Fuel Cycle Costs and Temperature Coefficients of Reactivity for $\mathrm{PuO}_{2}-\mathrm{SS}$ and $\mathrm{PuO}_{2}-\mathrm{UO}_{2}, "$ APDA$154,1963$.

8. Segal, B. M., "Seven-APDA--A Revised APDA 24-Group Cross Section Set," APDA Internal Memorandum P-65-98, 1965.

9. Trice, J. B., ASTM Special Technical Publication No. 276, pp 24-26, 1960.

10. Hughes, J。D。, and Swartz, R. B., BNL-325, 1958 .

11. Stehn, J. R., et al, BNL-325, Vol. III, 2nd ed., Suppl., 1965.

12. DiCola, G., and Rota, A., "Calculation of Differential Fast-Neutron Spectra from Threshold-Foil Activation Data by Least-Squares Series Expansion Method," Nuc. Sci. Engrg. 23, pp 344-353, 1965.

13. Davey, W. G., and Curran, R. N., "An Experimental Investigation of Some Sources of Error in the Measurement of Absolute Fission Ratios in Fast Reactors," ANL-6468, 1961.

14. Davey, W.G., "A Critical Comparison of Measured and Calculated Fission Ratios for ZPR-III Assemblies," ANL-6617, 1962. 